\title{
Genesis of an East Pacific Easterly Wave from a Panama Bight MCS: A Case Study Analysis from June 2012
}

\author{
Justin W. WhitAKer AND ERIC D. MALONEY \\ Department of Atmospheric Science, Colorado State University, Fort Collins, Colorado
}

(Manuscript received 31 January 2020, in final form 11 August 2020)

\begin{abstract}
This study investigates the transition of a Panama Bight mesoscale convective system (MCS) into the easterly wave (EW) that became Hurricane Carlotta (2012). Reanalysis, observations, and a convective-permitting Weather Research and Forecasting (WRF) Model simulation are used to analyze the processes contributing to EW genesis. A vorticity budget analysis shows that convective coupling and vortex stretching are very important to the transition in this case, while horizontal advection is mostly responsible for the propagation of the system. In the model, the disturbance is dominated by stratiform vertical motion profiles and a midlevel vortex, while the system is less top-heavy and is characterized by more prominent low-level vorticity later in the transition in reanalysis. The developing disturbance starts its evolution as a mesoscale convective system in the Bight of Panama. Leading up to MCS formation the Chocó jet intensifies, and during the MCS-to-EW transition the Papagayo jet strengthens. Differences in the vertical structure of the system between reanalysis and the model suggest that the relatively more bottom-heavy disturbance in reanalysis may have stronger interactions with the Papagayo jet. Field observations like those collected during the Organization of Tropical East Pacific Convection (OTREC) campaign are needed to further our understanding of this east Pacific EW genesis pathway and the factors that influence it, including the important role for the vertical structure of the developing disturbances in the context of the vorticity budget.
\end{abstract}

KEYWORDS: North Pacific Ocean; Tropics; Convection; Dynamics; Mesoscale systems; Waves, atmospheric

\section{Introduction}

Panama Bight mesoscale convective systems (MCSs) are important to the climate and weather of the east Pacific basin. The convective complexes contribute to yearly average rainfall totals ranging from approximately 2600 to $5250 \mathrm{~mm}$ in the region (Mapes et al. 2003a). Velasco and Fritsch (1987) and Mapes et al. (2003a) found that MCSs and precipitation in the Panama Bight generally occur year-round, but most often during boreal summer. Mapes et al. (2003b) describes a mechanism for MCS propagation away from the Colombian Andes into the Panama Bight, where the initiated convection moves offshore due to a gravity wave response from the elevated heating over land, and eventually becomes more organized into MCS structures during the night and early morning hours (Mapes et al. 2003a). These MCS features were characterized as wide convective cores and broad stratiform regions by Zuluaga and Houze (2015), indicative of mature convection, which can support the development of a midlevel vortex in the disturbance (e.g., Houze 2004). In addition, the Chocó jet, a westerly wind feature that peaks at $925 \mathrm{hPa}$ and extends across the Panama Bight and onshore plays a role in the heavy precipitation of the region (Poveda and Mesa 2000). The Chocó jet is supported by the strong SST gradient in the region (e.g., Poveda and Mesa 2000), with colder water to the south along the South American coast and warmer water to the north in the east Pacific basin and the Panama Bight (Fig. 1). The jet supports MCS development by directing low-level moisture into the Panama Bight and toward the Andes (Poveda and Mesa 2000; Zuluaga and Houze

Corresponding author: Justin W. Whitaker, jwwhit@atmos. colostate.edu
2015). Field campaigns like the Organization of Tropical East Pacific Convection (OTREC; https://www.eol.ucar.edu/field_ projects/otrec) project in summer 2019 (Fuchs-Stone et al. 2020) and the ChocoJet Experiment (CHOCO-JEX) in 2016 (Yepes et al. 2019) aimed to obtain in situ observations of the MCSs and Chocó jet to better understand their interactions.

East Pacific easterly waves (EWs) are also essential components of the boreal summer conditions in the basin. EWs in the east Pacific are coupled to convection (e.g., Rydbeck and Maloney 2015; Adames and Ming 2018) and are frequently identified as sources of east Pacific tropical cyclogenesis (e.g., Frank 1970; Molinari and Vollaro 2000; Dunkerton et al. 2009; Pasch et al. 2009). East Pacific EWs are composed of both deep convective and stratiform elements (Petersen et al. 2003), and have their strongest circulation at midlevels (Serra et al. 2008, 2010). EWs have periods of around five days and length scales on the order of $4000-5000 \mathrm{~km}$ (Serra et al. 2008) and tracks that are near and parallel to the Central American coastline (e.g., Thorncroft and Hodges 2001; Serra et al. 2010). East Pacific EWs rely primarily on convective invigoration and barotropic conversion for growth (e.g., Maloney and Hartmann 2001; Rydbeck and Maloney 2014), and environmental moisture anomalies are crucial for anomalous convection in the wave (Rydbeck and Maloney 2015). Further, modulations to the background environment of the basin by phenomena such as the Madden-Julian oscillation (MJO) and Caribbean low-level jet (CLLJ) significantly alter characteristics of the EWs (Maloney and Hartmann 2001; Crosbie and Serra 2014; Rydbeck and Maloney 2014, 2015; Whitaker and Maloney 2018). For example, anomalous low-level westerly phases of the MJO are associated with stronger waves that are driven more by convective invigoration and have tracks closer to Central America relative 


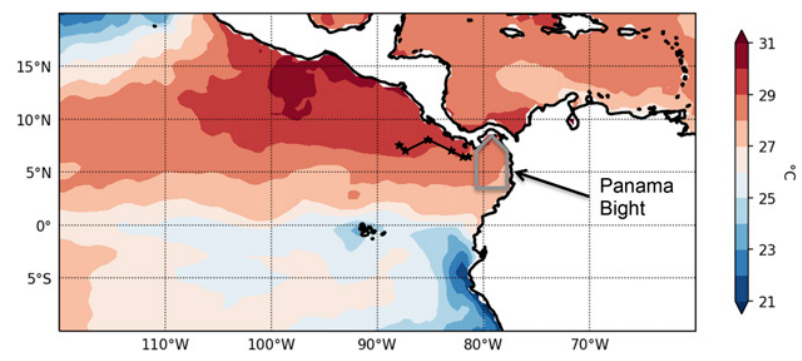

FIG. 1. ERA5 mean SST from 0000 UTC 5 Jun to 2100 UTC 19 Jun $2012\left({ }^{\circ} \mathrm{C}\right.$; color contours), WRF $500 \mathrm{hPa}$ unsmoothed vorticity maximum track for the vertical profile analysis (black stars), and approximate region considered the "Panama Bight" in this study (gray region). Black stars from east to west correspond to the locations of the WRF disturbance at 1800 UTC 11 Jun, 0000 UTC 12 Jun, 0600 UTC 12 Jun, 1200 UTC 12 Jun, 1800 UTC 12 Jun, and 0000 UTC 13 Jun, respectively.

to easterly periods (Crosbie and Serra 2014; Rydbeck and Maloney 2014, 2015; Whitaker and Maloney 2018). These enhanced EWs during westerly MJO phases also coincide with a marked increase in tropical cyclone activity in the basin (Maloney and Hartmann 2000), underscoring the need for further investigations into the life cycle of east Pacific EWs from EW genesis to development.

Recently, features and processes within the east Pacific region have been suggested as significant sources of EWs (e.g., Mozer and Zehnder 1996; Ferreira and Schubert 1997; Serra et al. 2010; Toma and Webster 2010; Rydbeck et al. 2017), as opposed to African EWs crossing Central America (e.g., Shapiro 1986; Pasch et al. 2009; Serra et al. 2010). Central American topography can play an important role in local EW genesis, with the mountains perturbing the incoming easterly flow into downstream eddies in idealized simulations (Zehnder 1991; Mozer and Zehnder 1996). The CLLJ and the Papagayo jet, an extension of the CLLJ through a gap in the mountains near Costa Rica and Nicaragua, were found at times to have a sign reversal of the meridional potential vorticity gradient near $700 \mathrm{hPa}$ in time-mean flows over a season from 15 June to 30 September 1991 (Molinari et al. 1997). Due to this sign reversal, Molinari et al. (1997) note that the Charney-Stern necessary condition for instability is met, which allows for synoptic disturbances like EWs to form in the jet regions. Serra et al. (2010) found that EW genesis does in fact occur in the Papagayo jet region, driven by barotropic energy conversions. Tropical cyclogenesis has also been linked to gap flows from the Papagayo jet, as well as the Tehuantepec jet in Mexico (e.g., Holbach and Bourassa 2014).

Convective development from the east Pacific intertropical convergence zone (ITCZ) and Panama Bight has also been shown to lead to EWs (e.g., Ferreira and Schubert 1997; Toma and Webster 2010; Rydbeck et al. 2017). Breakdown of ITCZ convection into EW-like disturbances was simulated in an idealized sense by Ferreira and Schubert (1997), and was cataloged in observations and reanalysis by Wang and Magnusdottir (2006). Near the Panama Bight, Kerns et al. (2008) found that the track density of midlevel vorticity maxima extends to the coasts of Panama and Colombia, and that this region is productive for eventual tropical cyclogenesis-vorticity signatures originating from this area are linked to tropical cyclone formation later on. In a modeling study, Rydbeck et al. (2017) analyzed the transition of Panama Bight MCSs into EWs from a composite perspective using a vorticity budget. In that study, horizontal vorticity advection and vortex stretching were found to be the primary contributors to transform the MCSs into EWs as they moved away from the Bight (Rydbeck et al. 2017). EW development from an initial convective heat source has been simulated over Africa (Thorncroft et al. 2008), and more recently for the Panama Bight (Torres and Thorncroft 2018) in an idealized primitive equation model.

The purpose of this study is to investigate the Panama Bight MCS to EW growth mechanism in a case study of the EW that led to Hurricane Carlotta (2012). The case will be first analyzed with reanalysis and observational data, before being examined in detail with a regional convective-permitting simulation. The simulation will be used to better understand the role of convective processes in the MCS transition and this impact will be quantified through a vorticity budget. While the reanalysis data used rely on parameterized convection, the model simulation will be able to better resolve convection in the developing disturbance and hence should provide a potentially more realistic picture of the role of convection in this transition. Further, this simulated case will be compared with the composite results for the MCS-to-EW transition found in Rydbeck et al. (2017). Section 2 of this paper discusses the data, the modeling setup, and the methodology applied in this study. Sections 3 and 4 describe the case study and the results of the vorticity budget, respectively. Section 5 investigates possible interactions of the disturbance with low-level wind jets, while section 6 provides a discussion of the results.

\section{Data, model setup, and methodology}

To select a case of EW genesis from a Panama Bight MCS, the National Hurricane Center's Tropical Cyclone Reports (https://www.nhc.noaa.gov/data/tcr/) and NASA Worldview satellite imagery (https://worldview.earthdata.nasa.gov/) were first used. The disturbance that contributed to the development of Hurricane Carlotta in June 2012 seemed a reasonable instance of this mechanism, as the NHC report states, "the genesis of Carlotta can be traced back to an area of disturbed weather that moved westward from Colombia" (Pasch and Zelinsky 2012). True color satellite imagery from NASA Worldview also supports this notion by highlighting a cloud cluster in the Panama Bight on 11 June that expands in size as it moves northwestward and has a reminiscent tilt from the southwest to northeast on 13 June (Fig. 2), like previously studied EWs (e.g., Serra et al. 2008).

To investigate the formation of the EW prior to Carlotta, reanalysis, observations, and a model simulation are employed and compared. First, the observational and reanalysis investigation of the case consists of data from the new European Centre for Medium-Range Weather Forecasts reanalysis data [ERA5; Copernicus Climate Change Service (C3S); C3S 2017] and precipitation data from the NOAA Climate Prediction 


\section{June 2012}

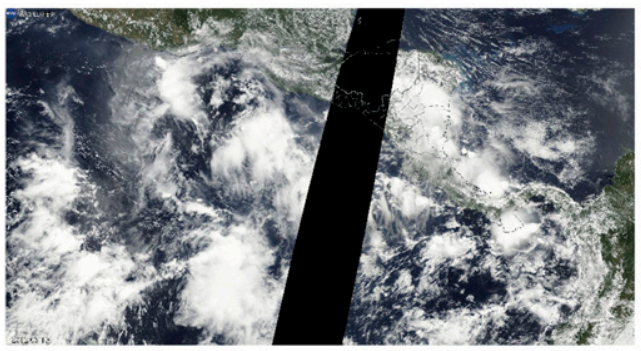

11 June 2012

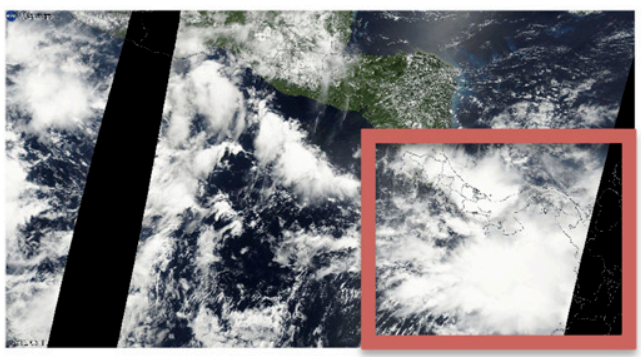

12 June 2012

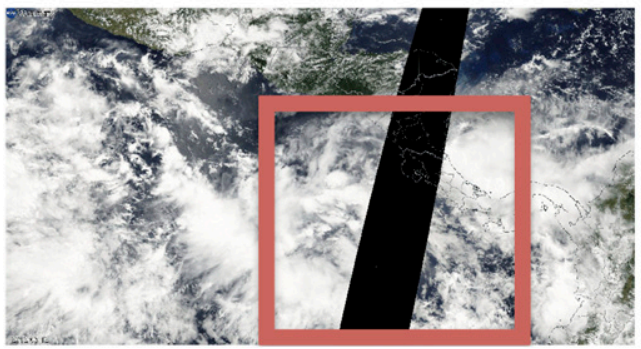

13 June 2012

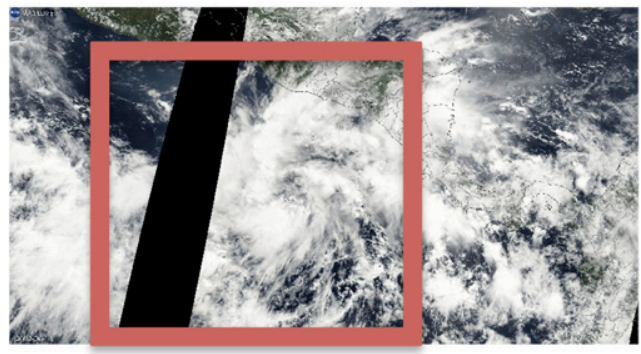

14 June 2012

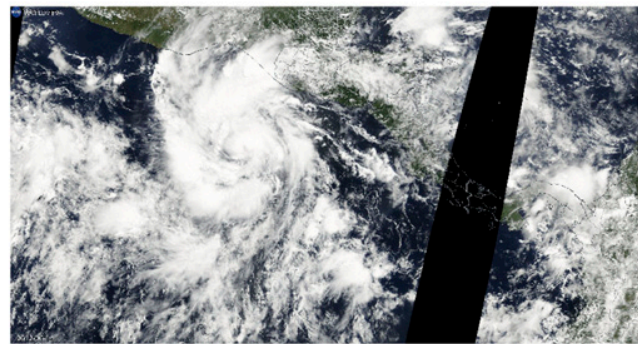

15 June 2012

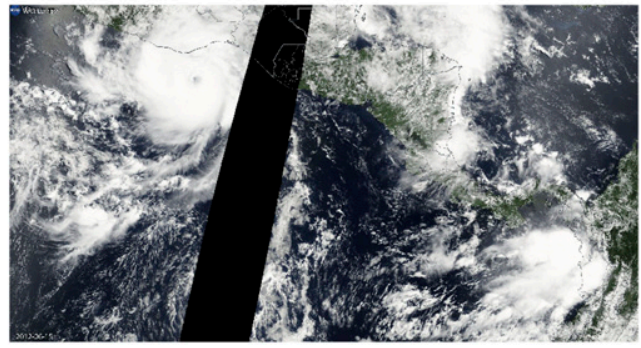

FIG. 2. Terra/MODIS true color imagery of the development of Hurricane Carlotta (10-15 Jun 2012). Red boxes indicate the region of the developing disturbance. Imagery was taken from NASA Worldview.

Center (CPC) morphing technique dataset (CMORPH; Joyce et al. 2004). The ERA5 data for this analysis consist of 23 vertical levels from 1000 to $200 \mathrm{hPa}$, a spatial resolution of $0.5^{\circ}$, and a temporal resolution of $3 \mathrm{~h}$ from 0000 UTC 5 June to 2100 UTC 19 June. Observational sources input to ERA5 include data from satellites, buoys, radiosondes, and aircraft (C3S 2017). The CMORPH precipitation data have a spatial resolution of $0.25^{\circ}$ and the same temporal resolution and duration as the ERA5 data.

To simulate the evolution of the MCS into an EW, the Weather Research and Forecasting (WRF) ARW Model, version 3.9.1.1 (Skamarock et al. 2008), is used. The model setup and simulation details are displayed in Table 1 , and highlight that WRF is run at convective-permitting scales (4 km horizontally, 40 vertical levels) without a cumulus or shallow cumulus parameterization to better represent the convective development of the system in the east Pacific. This model setup contrasts with that of Rydbeck et al. (2017), which investigated MCS-to-EW transitions in a composite sense over several years in WRF with parameterized convection and an inner domain grid spacing of $18 \mathrm{~km}$. In addition to employing a higher spatial resolution and removing the cumulus parameterization, this study uses the Thompson et al. (2008) microphysics

TABLE 1. WRF Model and simulation setup.

\begin{tabular}{|c|c|}
\hline Model & $\begin{array}{l}\text { WRF-ARW V3.9.1.1 (Skamarock } \\
\text { et al. 2008) }\end{array}$ \\
\hline Domain & $2^{\circ}-14^{\circ} \mathrm{N}, 100^{\circ}-74^{\circ} \mathrm{W}$ \\
\hline Simulation dates & 1200 UTC 11 Jun-0000 UTC 15 Jun 2012 \\
\hline Input interval & $10800 \mathrm{~s} ;$ input data from ERA5 $\left(0.5^{\circ}\right)$ \\
\hline Time step & $30 \mathrm{~s}$ \\
\hline Resolution & $4 \mathrm{~km}$ (horizontal); 40 vertical levels \\
\hline $\begin{array}{l}\text { Cumulus } \\
\text { parameterization }\end{array}$ & None \\
\hline Microphysics & Thompson (Thompson et al. 2008) \\
\hline Radiation & CAM (Collins et al. 2004) \\
\hline Land surface model & Noah (Tewari et al. 2004) \\
\hline PBL scheme & YSU (Hong et al. 2006) \\
\hline
\end{tabular}


scheme instead of the WRF single-moment 6-class scheme, forces and initializes the model with an improved and higher-resolution reanalysis (ERA5), and simulates a single disturbance over a smaller domain. The Thompson et al. (2008) scheme was selected due to its effectiveness in simulating MCS development (K. L. Rasmussen 2018, personal communication) and has been used in higher resolution simulations of MCSs (e.g., Rasmussen and Houze 2016). Although the Thompson et al. (2008) scheme has been shown to lead to more top-heavy structures and MCS organization (Feng et al. 2018), a sensitivity test with the WRF singlemoment 6-class microphysics scheme yielded similar results to the Thompson et al. (2008) scheme used in this study. The input data for the simulation are ERA5 data that are three hourly, has $0.5^{\circ}$ horizontal grid spacing, and has 29 pressure levels. ERA5 sea surface temperature data are used at the same temporal and horizontal resolution and are updated every $24 \mathrm{~h}$. The ERA5 input data are used for the lateral boundary forcing for this single domain, nonnested run and are used to initialize the simulation. Additionally, the simulation begins at 1200 UTC 11 June after the MCS disturbance has formed (e.g., Fig. 2) and is run to 0000 UTC 15 June, as we are most interested in the model's representation of the MCS-to-EW transition as opposed to the initiation of the MCS convection prior to its evolution. To account for potential model spinup time, the analysis of the WRF run begins at 1800 UTC 11 June. Additionally, the reasonable representation of the MCSto-EW transition in WRF compared to ERA5 gives confidence to this initialization approach.

For a more direct comparison to the ERA5 and CMORPH data, model output and simulated precipitation rates were degraded to approximate resolutions of $0.5^{\circ}$ and $0.25^{\circ}$, respectively, by averaging the higher resolution model data to these grid sizes. Further, for displaying the model data in Hovmöller and plan view formats, a spatial Gaussian filter was used to smooth the data. For the WRF Hovmöller diagram, vorticity anomalies were smoothed using a filter with a standard deviation of $\sigma=0.5$ (corresponding to a filter spatial standard deviation of $0.25^{\circ}$ and temporal standard deviation of $1.5 \mathrm{~h}$ ), while for all model plan view figures and the ERA5 vorticity (in Figs. 4 and 11) the contoured fields were smoothed using a filter with a standard deviation of $\sigma=0.6$ (corresponding to a filter spatial standard deviation of $0.3^{\circ}$ for the $0.5^{\circ}$ resolution data and $0.15^{\circ}$ for the $0.25^{\circ}$ resolution data). In this study, anomalies are calculated relative to the time mean over each respective time period (ERA5 and CMORPH: 0000 UTC 5 June to 2100 UTC 19 June; WRF: 1200 UTC 11 June to 0000 UTC 15 June). The results of ERA5 anomalies are fairly similar when calculated over the WRF simulation time period. Further, anomalous vertical profiles for the disturbance are calculated by taking the area-average at each pressure level over an approximately $2^{\circ} \times 2^{\circ}$ box centered on the unsmoothed $500 \mathrm{hPa}$ vorticity anomaly maximum, and then subtracting off the respective time mean over that specific region at all levels. Finally, for analyzing the Chocó and Papagayo jets, a time series of the area-averaged $925 \mathrm{hPa}$ horizontal vector wind speed was calculated over the regions $3^{\circ}-7^{\circ} \mathrm{N}, 77^{\circ}-85^{\circ} \mathrm{W}$ and $9^{\circ}-13^{\circ} \mathrm{N}, 86^{\circ}-89^{\circ} \mathrm{W}$, respectively. The Papagayo jet averaging region is the same region that was defined in Whitaker and Maloney (2018) for a CLLJ index.

\section{Case study overview}

The disturbance leading to Hurricane Carlotta in June 2012 highlights the broader implication of the EW genesis mechanism proposed by Rydbeck et al. (2017) (that a Panama Bight MCS can develop into an EW, which then transitions into a tropical cyclone) and is also documented in Pasch and Zelinsky (2012). According to the National Hurricane Center's report on Carlotta (Pasch and Zelinsky 2012), the disturbance "can be traced back to an area of disturbed weather that moved westward from Colombia to near and just south of Panama on 11 June." In addition, Pasch and Zelinsky (2012) state that "extrapolation and analyses ... suggest that this system was associated with a tropical wave that departed Africa in early June, although this is uncertain since the wave became ill-defined over the central Atlantic." Figure 2 shows the progression of a Panama Bight MCS into Hurricane Carlotta through true color satellite imagery (human-vision-related visible wavelengths) from NASA Worldview. On 10 June, sporadic deep convection is occurring across the east Pacific, while the Panama Bight region is relatively clear. On the next day, an MCS can clearly be identified in the imagery as a circular region of deep clouds, and by 13 June the system has moved to the northwest and transitioned into an EW having a larger area of convection that is oriented from southwest to northeast, reminiscent of the EW structures found by Serra et al. (2008), Rydbeck and Maloney (2014), and others. Carlotta achieved tropical storm and hurricane strength on 0600 UTC 14 June and 1200 UTC 15 June, respectively (Pasch and Zelinsky 2012), and an eye is visible in the satellite imagery on 15 June (Fig. 2). Ultimately, Carlotta is reported to have made landfall near Puerto Escondido, Mexico, and reached its maximum wind speed of $109 \mathrm{mph}(1 \mathrm{mph} \approx$ $0.48 \mathrm{~m} \mathrm{~s}^{-1}$ ) $4 \mathrm{~h}$ prior to landfall (Pasch and Zelinsky 2012). Although this study focuses on the growth of the MCS into an $\mathrm{EW}$, the fact that a landfalling hurricane was produced as a result of this EW further underscores the importance of investigating this pathway to EW genesis.

Figure 3 highlights the progression of the MCS in ERA5 and CMORPH and the WRF simulation through Hovmöller diagrams (averaged from $11^{\circ}$ to $2.5^{\circ} \mathrm{N}$ ) of precipitation rate and anomalous $700 \mathrm{hPa}$ vorticity (relative to each respective time mean). Analyses at $700 \mathrm{hPa}$ have been performed in prior studies to feature EW circulations (Serra et al. 2008, 2010; Rydbeck and Maloney 2014) and $700 \mathrm{hPa}$ is used to highlight the development of the system from MCS to EW as well as the transition from EW to tropical cyclone. In ERA5 and CMORPH, the MCS feature starting at $1200 \mathrm{UTC} 11$ June between $80^{\circ}$ and $85^{\circ} \mathrm{W}$ has rain rates up to $6 \mathrm{~mm} \mathrm{~h}^{-1}$ that are roughly in phase with the vorticity signature, while at later times starting around 0000 UTC 13 June the EW has lower rain rates and generally higher vorticity. Further, the continuous signal in both CMORPH precipitation and ERA5 vorticity from around $80^{\circ}$ to $91^{\circ} \mathrm{W}$ over 2 days displays the propagation of the disturbance from the Panama Bight at an approximate phase speed of $7 \mathrm{~ms}^{-1}$. An extension of the Hovmöller diagram analysis further back in time and to the east (not shown) reaffirms the findings of Pasch and Zelinsky (2012) that there was not a definitive African EW precursor to this disturbance, and points to this EW likely being formed locally within the east Pacific. The WRF Model produces a similar 

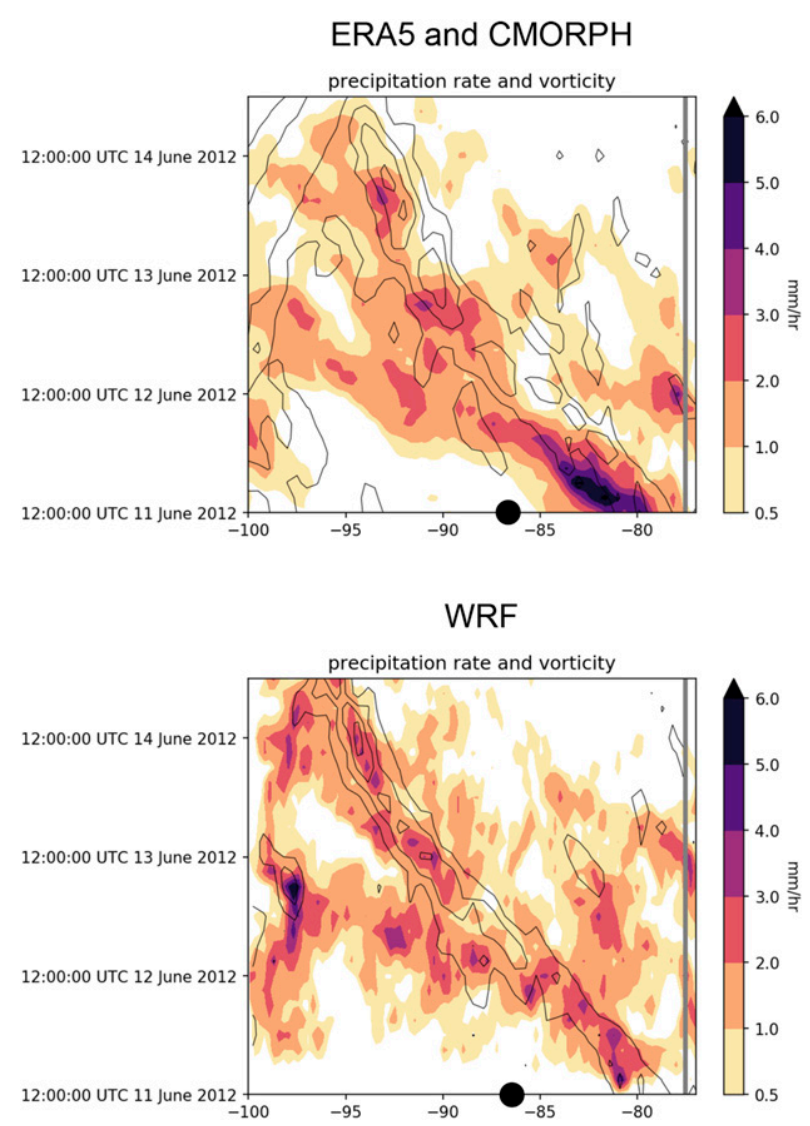

FIG. 3. Hovmöller diagrams of precipitation rate $\left(\mathrm{mm} \mathrm{h}^{-1}\right.$; color contours) and anomalous $700 \mathrm{hPa}$ relative vorticity ( $\mathrm{s}^{-1}$; line contours; $1 \times 10^{-5}$ to $7 \times 10^{-5} \mathrm{~s}^{-1}$ by $2 \times 10^{-5} \mathrm{~s}^{-1}$ ) for (top) ERA5 and CMORPH and (bottom) the WRF simulation. Data are averaged from $11^{\circ}$ to $2.5^{\circ} \mathrm{N}$, and the gray vertical line at $77.5^{\circ} \mathrm{W}$ represents the Pacific coast of South America. The black dots on the longitude axis represent the approximate longitude of the vorticity disturbance at the time of easterly wave genesis (1800 UTC 12 Jun 2012).

Hovmöller diagram to that of ERA5 and CMORPH and reasonably reproduces the growth of the MCS into an EW. For the simulated MCS, the precipitation is lighter than in observations to the east of $85^{\circ} \mathrm{W}$, with maximum values only up to $4 \mathrm{~mm} \mathrm{~h}^{-1}$, which may be a consequence of using the Thompson et al. (2008) microphysics scheme. As will be described with Fig. 5, a vorticity feature that is tilted from southwest to northeast becomes apparent by 1800 UTC 12 June. This tilted vorticity structure is consistent with the formation of an EW and will be used as the metric for determining EW formation in this study. The approximate longitude of EW genesis is highlighted in Fig. 3 and occurs near $86^{\circ}$ to $87^{\circ} \mathrm{W}$. The EW feature in WRF has similar precipitation values to the observations. Further, the model produces a slightly more coherent propagation of the vorticity feature in the disturbance when compared to ERA5.

Figures 4 and 5 provide a map of the evolution of $700 \mathrm{hPa}$ vorticity anomalies and precipitation for the disturbance in both observations (Fig. 4) and in the WRF simulation (Fig. 5).
In Fig. 4 at 0000 UTC 11 June, the initial convection is beginning to develop along the western coast of Colombia and $12 \mathrm{~h}$ later has moved offshore forming an MCS with CMORPH rain rates over $20 \mathrm{~mm} \mathrm{~h}^{-1}$, having similar timing to the diurnal cycle results of Mapes et al. (2003a). For example, Mapes et al. (2003a) found that Panama Bight precipitation maximized around 0600 to 0800 local time in the mean diurnal cycle, which is close to the time (1200 UTC 11 June) that the MCS structure is shown in Fig. 4. Between 0000 UTC 12 June and 0000 UTC 13 June the disturbance moves parallel to the Central American coastline and begins transitioning with the development of a broad region of enhanced vorticity. By 0000 UTC 13 June an EW structure of southwest to northeast tilted vorticity has formed at $700 \mathrm{hPa}$, which has precipitation within and around the disturbance. From 0000 UTC 13 June to 1200 UTC 14 June, the EW disturbance strengthens into Tropical Storm Carlotta (Pasch and Zelinsky 2012).

Figure 5 shows that the initialized MCS also grows into an EW in the WRF simulation. The simulated MCS in WRF appears to be weaker than in observations, with generally lower precipitation at 1800 UTC 11 June versus the mature MCS at 1200 UTC 11 June in Fig. 4. It is important to note that due to the chaotic nature of convection, we do not necessarily expect the model to perfectly match the observations and reanalysis. Between 0000 UTC 12 June and 0000 UTC 13 June the transition from an MCS into an EW features narrow regions of stronger precipitation that are aligned with the vortex axis, particularly at 0600 UTC (not shown) and 1200 UTC. This behavior is not as apparent in observations and ERA5. The enhanced precipitation collocated with the vorticity feature suggests that deep convection and the resulting stratiform precipitation in WRF could be important to the MCS-to-EW transition. Rydbeck and Maloney (2015) showed that deep convection is important to EW development, while persistent stratiform precipitation and heating from an MCS can help maintain a midlevel vortex (e.g., Houze 2004). As will be shown later, vertical profiles of the disturbance suggest strong stratiform support in growing the disturbance. By 1800 UTC 12 June, the $700 \mathrm{hPa}$ vorticity is tilted horizontally from southwest to northeast to form an EW (not shown) and the horizontally tilted structure persists over the next $12 \mathrm{~h}$ as the system strengthens (Fig. 5). The simulated disturbance then transitions into a tropical cyclone-like structure by 1200 UTC 14 June, matching the progression shown in Fig. 4. These results support the hypothesis for EW genesis via MCS growth proposed by Rydbeck et al. (2017) and highlight the large role that convective processes seem to play in this process in WRF. In summary, the timeline of this process can be broken into three sections: MCS stage up to 0000 UTC 12 June, MCS-to-EW transition from 0000 to 1800 UTC 12 June, and EW formation at 1800 UTC 12 June with subsequent development.

\section{Vorticity budget}

To further investigate the development of the MCS into an $\mathrm{EW}$, a vorticity budget at $500 \mathrm{hPa}$ is calculated. This pressure level is chosen to better analyze the transition of the MCS into an EW, as the vortex tends to generally be maximized near 


\section{ERA5 and CMORPH}
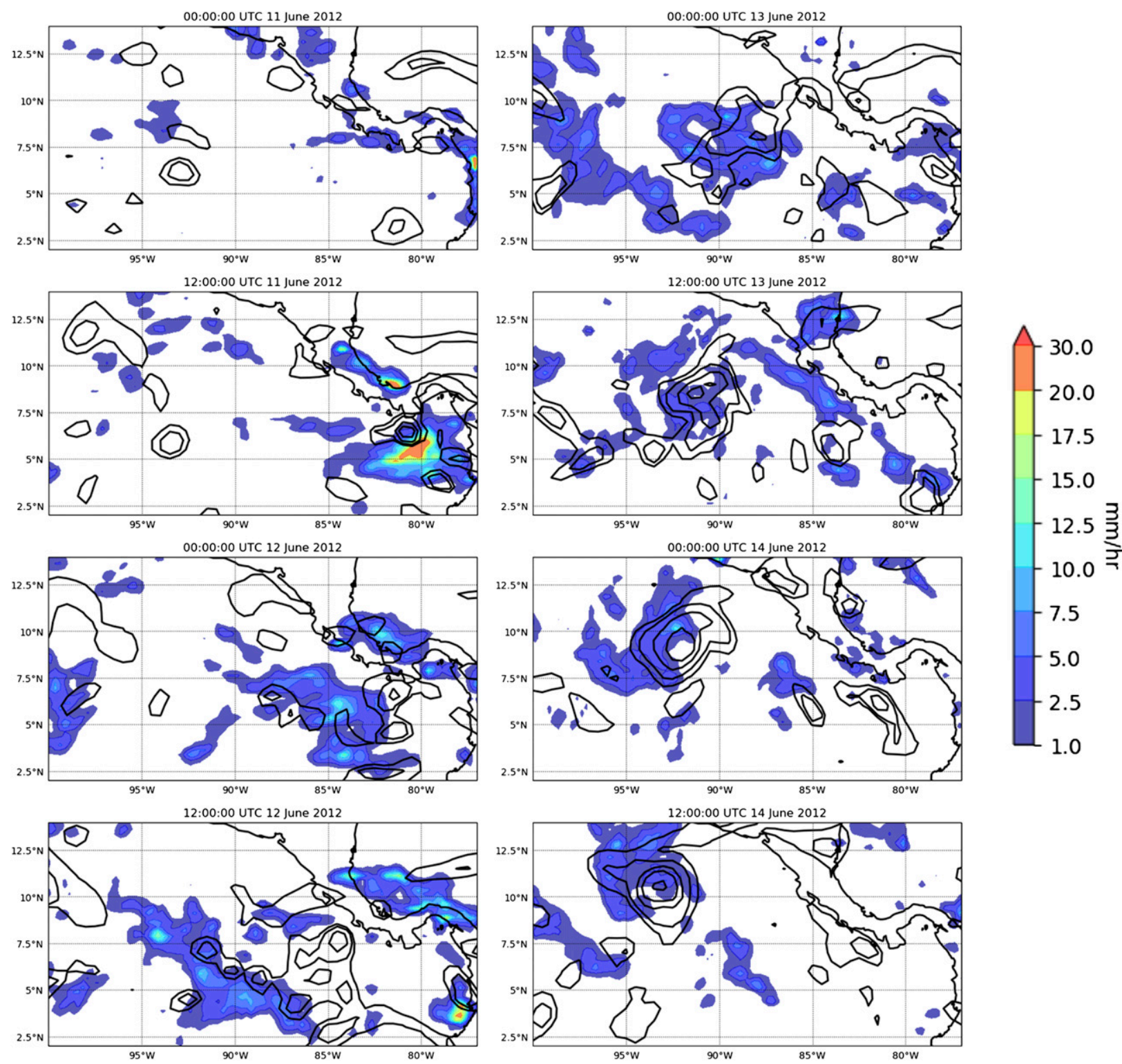

FIG. 4. ERA5 $700 \mathrm{hPa}$ relative vorticity anomalies ( $\mathrm{s}^{-1}$; line contours) and CMORPH precipitation rate ( $\mathrm{mm} \mathrm{h}^{-1}$; color contours) for the developing disturbance. Vorticity contours are plotted for $2.5,5,10,15,25,45$, and $65 \times 10^{-5} \mathrm{~s}^{-1}$.

$500 \mathrm{hPa}$ during that period (Figs. 13, 14), and to compare against the more generalized results in Rydbeck et al. (2017). Similar to Rydbeck et al. (2017), the vorticity budget equation is given as

$$
\begin{aligned}
\underbrace{\frac{\partial \zeta_{z}}{\partial t}}_{\text {Time tendency }}= & -\underbrace{\left(u \frac{\partial \eta}{\partial x}+v \frac{\partial \eta}{\partial y}\right)}_{\text {Horizontal advection }}+\underbrace{\eta \frac{\partial \omega}{\partial p}}_{\text {Stretching }} \\
& +\underbrace{\left[\frac{\partial}{\partial x}\left(-\zeta_{u} \frac{\omega}{\rho g}\right)+\frac{\partial}{\partial y}\left(-\zeta_{v} \frac{\omega}{\rho g}\right)\right]}_{\text {Tilting }}+\underbrace{R}_{\text {Residual }},
\end{aligned}
$$

where $\zeta_{z}=(\partial v / \partial x-\partial u / \partial y)$ is the vertical vorticity, $u$ is the zonal wind, $v$ is the meridional wind, $\eta=\zeta_{z}+f$ is the absolute vorticity, $\omega$ is the vertical pressure velocity, $p$ is pressure, $\zeta_{u}=$ $[(-1 / \rho g)(\partial \omega / \partial y)-(\partial v / \partial p)(-\rho g)]$ is the zonal component of vorticity, $\zeta_{v}=[(\partial u / \partial p)(-\rho g)-(-1 / \rho g)(\partial \omega / \partial x)]$ is the meridional component of vorticity, $g$ is the acceleration due to gravity, and $\rho=p / \mathrm{RT}$ is the density of air, with $R=$ $287 \mathrm{~J} \mathrm{~kg}^{-1} \mathrm{~K}^{-1}$ and $T$ being temperature. The vorticity equation describes the evolution of vertical vorticity that is modulated by the sum of the horizontal advection of vorticity, vortex stretching and tilting, and a budget residual which accounts for factors like friction and turbulent mixing. The budget residual 
WRF
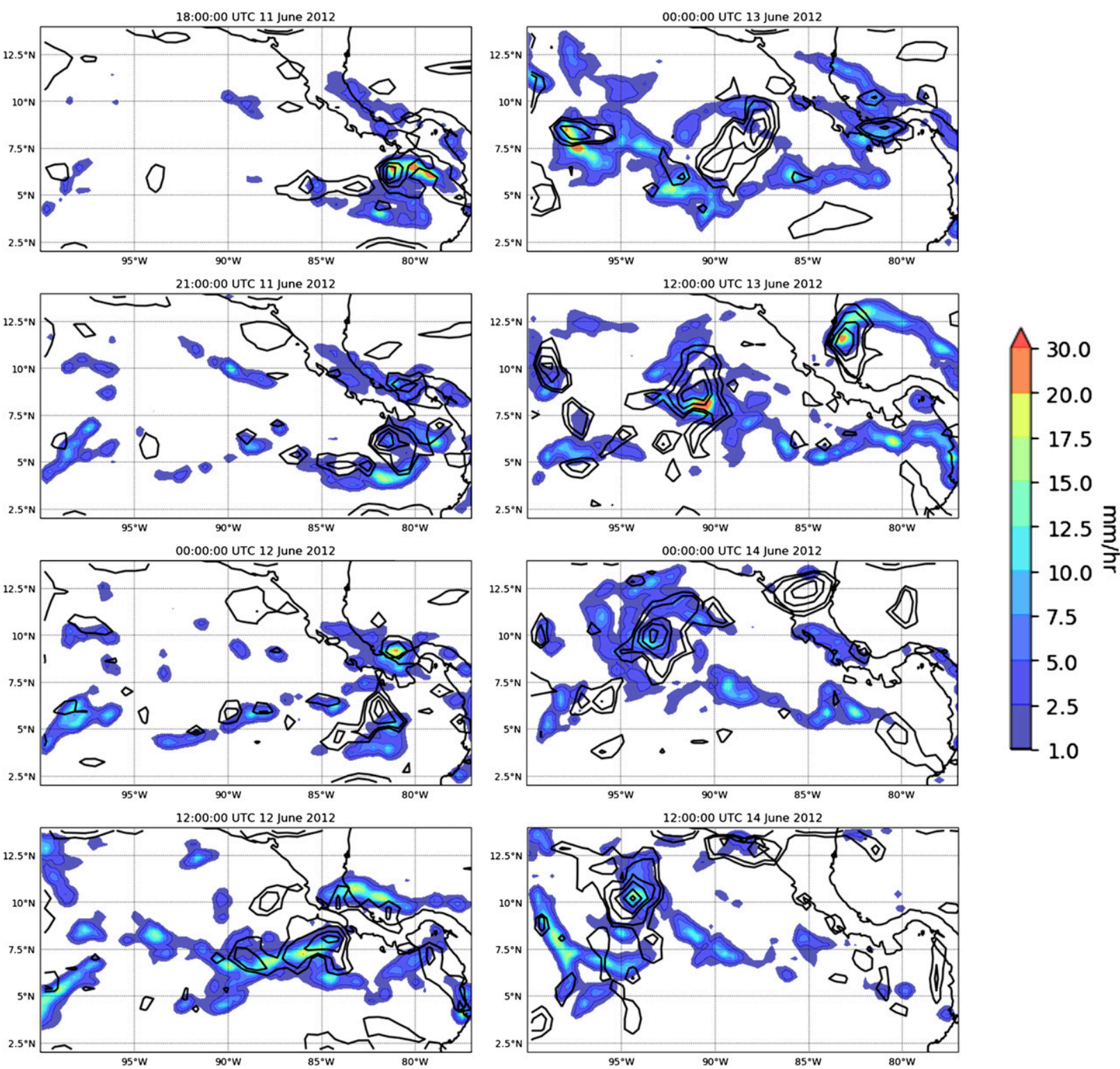

FIG. 5. WRF $700 \mathrm{hPa}$ relative vorticity anomalies $\left(\mathrm{s}^{-1}\right.$; line contours) and precipitation rate $\left(\mathrm{mm} \mathrm{h}^{-1}\right.$; color contours) for the developing disturbance. Vorticity contours are plotted for $2.5,5,10,15,25,45$, and $65 \times 10^{-5} \mathrm{~s}^{-1}$.

is of the same order of magnitude as the other budget terms, but this analysis will focus primarily on horizontal advection and vortex stretching, the important terms in this process identified by Rydbeck et al. (2017).

\section{a. WRF}

Figures $6-8$ provide the vorticity budget analysis for the convective-permitting WRF simulation across the MCS-toEW transition time period noted in Fig. 5. Vorticity budget terms in Figs. 6-8 are not decomposed into a perturbation and background, with the total field plotted. The total field budget terms closely resemble the time-mean anomalies. For the vorticity budget results, we focus primarily on the WRF simulation as the convective processes in the model should provide a more realistic representation of the role of convection as well as its vertical structure in the MCS-to-EW transition versus that from ERA5 where convective heating is parameterized, which is of particular concern given the data sparseness of the east Pacific. We provide more discussion below about the different realizations of the vertical heating structure in WRF and ERA5 and implications for the vorticity budget. We also acknowledge the chaotic nature of tropical convection in this region, and that even a different realization of the model may produce 


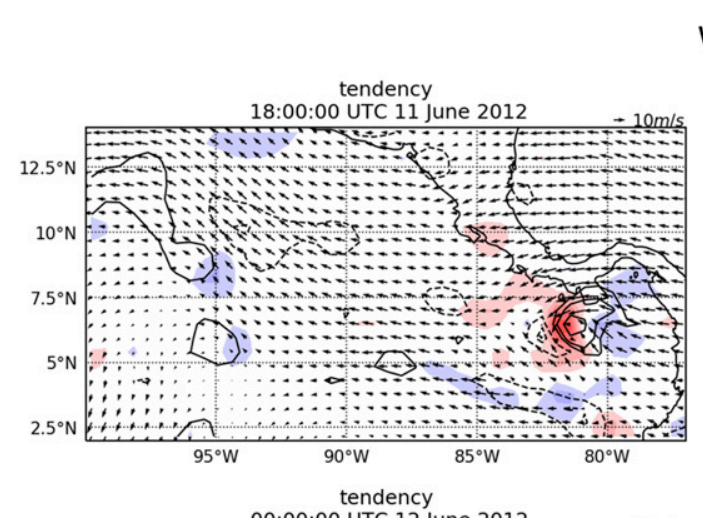

\section{WRF}
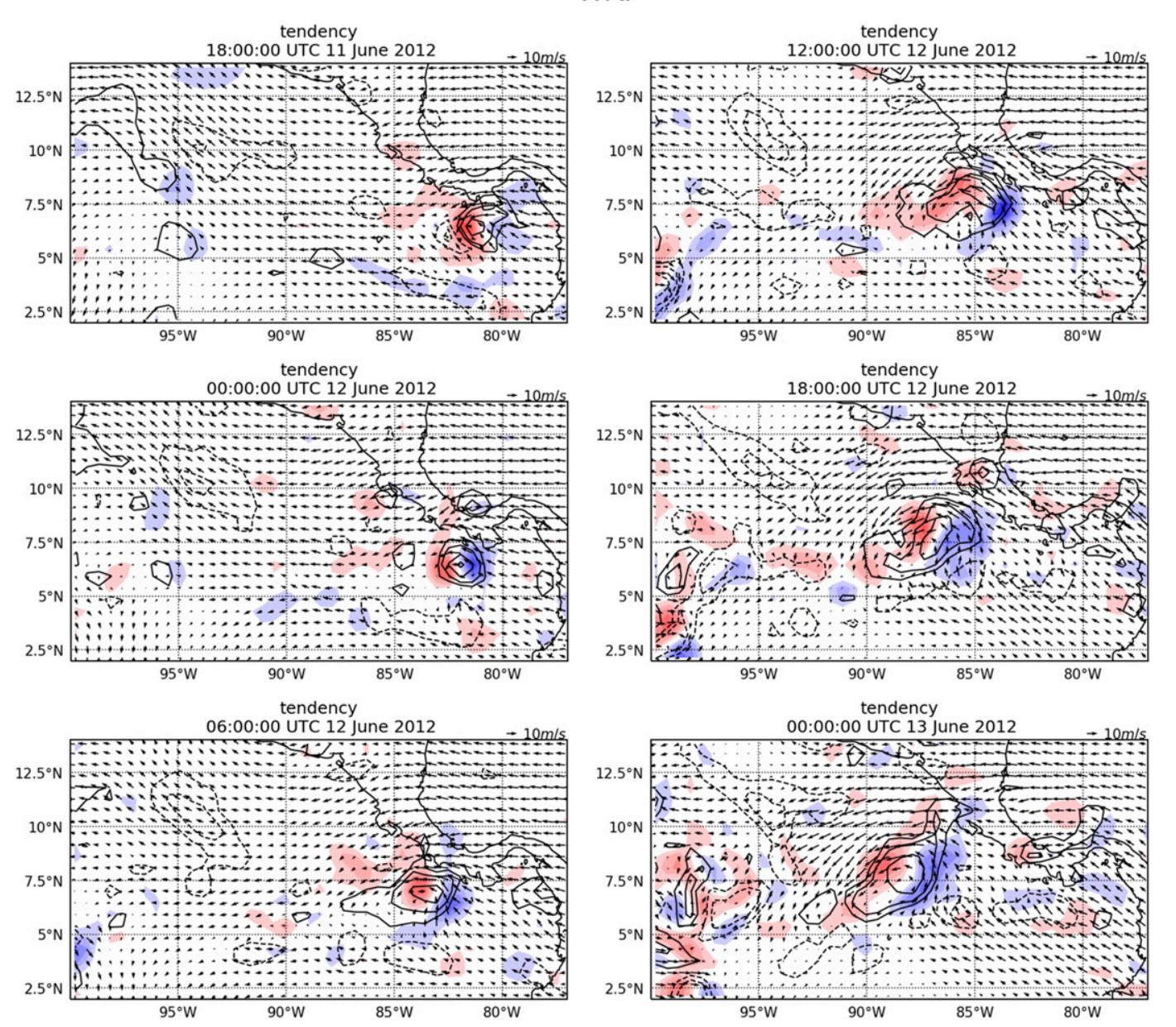

$-8 \mathrm{e}-04$

FIG. 6. WRF total $500 \mathrm{hPa}$ vorticity time tendency ( $\mathrm{s}^{-1} \mathrm{day}^{-1}$; color contours), anomalous $500 \mathrm{hPa}$ relative vorticity ( $\mathrm{s}^{-1}$; line contours), and total $500 \mathrm{hPa}$ wind $\left(\mathrm{m} \mathrm{s}^{-1}\right.$; vectors; reference vector of $10 \mathrm{~m} \mathrm{~s}^{-1}$ in the upper right of each panel). Relative vorticity contours are plotted for $\pm 2.5,5,10,15,25,45$, and $65 \times 10^{-5} \mathrm{~s}^{-1}$.

somewhat different convective evolution and effect on the vorticity budget. However, we are reassured through examination of Fig. 3 that the WRF simulation we examine produces a plausible evolution of the vorticity growth of the disturbance given the similarities relative to reanalysis in the vorticity field and relationship to observed precipitation.

Figure 6 shows the $500 \mathrm{hPa}$ vorticity tendency term and vorticity anomaly for the disturbance. During the MCS phase at 1800 UTC 11 June, the vorticity anomaly is fairly circular with strong positive tendency on the western side. Over the next $24 \mathrm{~h}$, the small disturbance moves northwestward, expands and horizontally tilts. A positive vorticity tendency tends to occur on the leading side with a negative tendency on the trailing side, consistent with propagation. However, a positive vorticity tendency is also often found collocated with the vortex center during these times, implying vortex growth. Overall, a strong positive tendency near the disturbance center as it leaves the coast and a tendency dipole agree with the composite results of (Rydbeck et al. 2017); however, the findings in this study are likely noisier due to the nature of a case study.

Figures 7 and 8 depict the horizontal advection of vorticity and vortex stretching for the simulated disturbance, respectively. For horizontal advection, the pattern of positive (negative) values on the leading (trailing) sides of the system reflect the portion of the tendency in Fig. 6 that are consistent with propagation, especially at the EW stage. While Rydbeck et al. (2017) found that the initial mesoscale vortex expands in the composite over many events due to differences in horizontal advection on either side of the system, with horizontal advection contributing to vortex growth, this process does not appear as prominent in the model simulation for this single case. For example, Rydbeck et al. (2017) show strong positive horizontal advection leading the midlevel vorticity anomaly that is larger in absolute value than the trailing negative advection. In this case study, the leading positive horizontal advection seems to be similar in absolute value, or even weaker than, the trailing negative advection feature (Fig. 7). However, vortex stretching associated with convective activity appears to have a consistent 
WRF
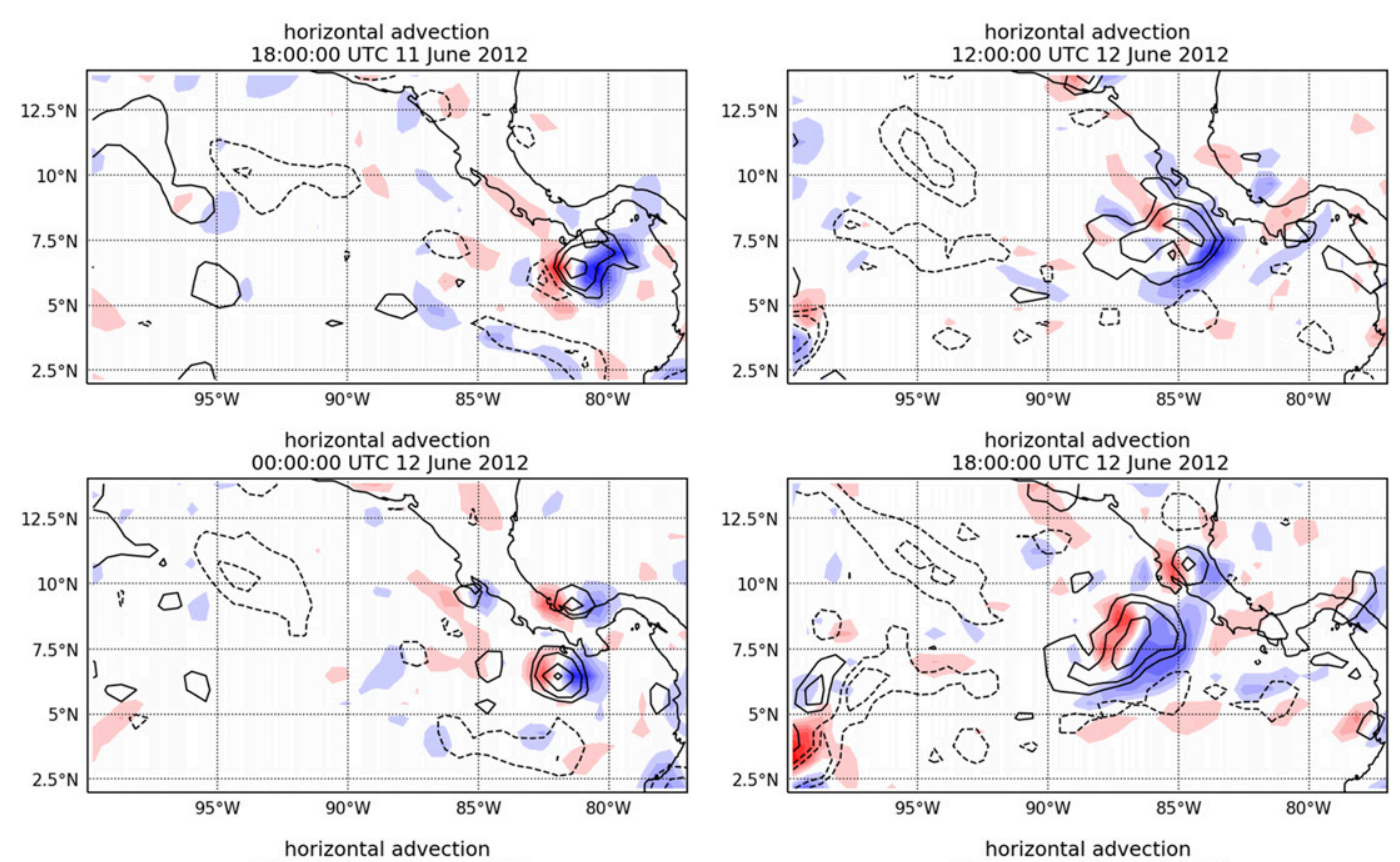

$8 e-04$
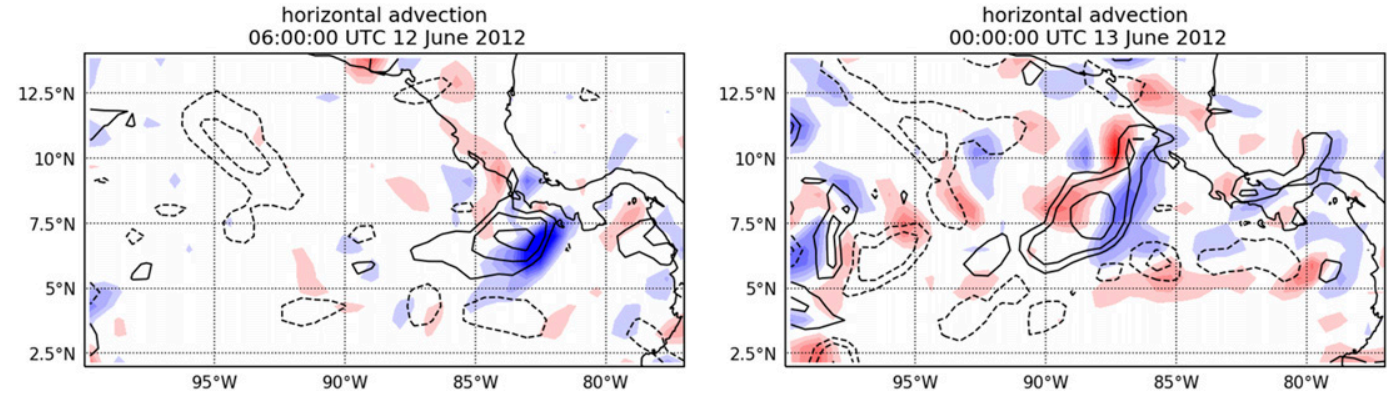

FIG. 7. WRF total $500 \mathrm{hPa}$ horizontal advection of vorticity $\left(\mathrm{s}^{-1}\right.$ day $^{-1}$; color contours) and anomalous 500 hPa relative vorticity ( $\mathrm{s}^{-1}$; line contours). Relative vorticity contours are plotted for $\pm 2.5,5,10,15,25,45$, and $65 \times 10^{-5} \mathrm{~s}^{-1}$.

impact on vortex growth in our case study (Fig. 8). A positive stretching tendency first occurs within the initial MCS feature at 1800 UTC 11 June allowing the vortex to intensify. During the transition period from 0000 to 1800 UTC 12 June, a strong positive stretching feature occurs within the vorticity anomaly and on the southwest and northeast sides of the system. This promotes wave tilting and eddy kinetic energy growth by eddymean flow interactions in a region of background cyclonic shear of the mean zonal wind (Rydbeck and Maloney 2015). To this end, positive stretching in these regions will support an expansion of the vortex to the southwest and northeast, generating a horizontal tilt. Further, a cyclonic wave tilted from southwest to northeast in a favorable mean cyclonic shear environment will acquire eddy kinetic energy through barotropic energy conversions (e.g., Maloney and Hartmann 2001; Serra et al. 2010). Thus, this result supports the findings of Fig. 5 that a strong coupling between convective processes and the vortex in the model aids EW genesis from the MCS, and is further highlighted by the elevated rain rates in Fig. 5 being collocated with regions of strong vortex stretching in Fig. 8, particularly at 1800 UTC 11 June and 0600 and 1200 UTC
12 June and vertical Q1 profiles of the system center indicative of convective activity (not shown). Further, the locations of strong stretching within and at the flanks of the vortex center are consistent with the composite results of Rydbeck et al. (2017) that stretching contributes to the strengthening and expansion of the system, especially considering that the simulation is run at convective-permitting scales. Finally, while vortex tilting in the simulation weakly supports MCS intensification in the initial stages and also produces positive vorticity tendency on the leading side of the system in its development, tilting does not seem to play as large of a role in the MCS transition to an EW compared to stretching (not shown).

\section{b. Vertical profiles}

In addition to the $500 \mathrm{hPa}$ plan-view snapshots of the vorticity budget, anomalous area-averaged vertical profiles of the budget terms were calculated for the MCS-to-EW transition in WRF (Fig. 9). The vertical profile anomalies for the disturbance are calculated via a Lagrangian analysis by taking the area average at each vertical level across a $2^{\circ} \times 2^{\circ}$ box centered on the unsmoothed $500 \mathrm{hPa}$ vorticity anomaly maximum for 


\section{WRF}
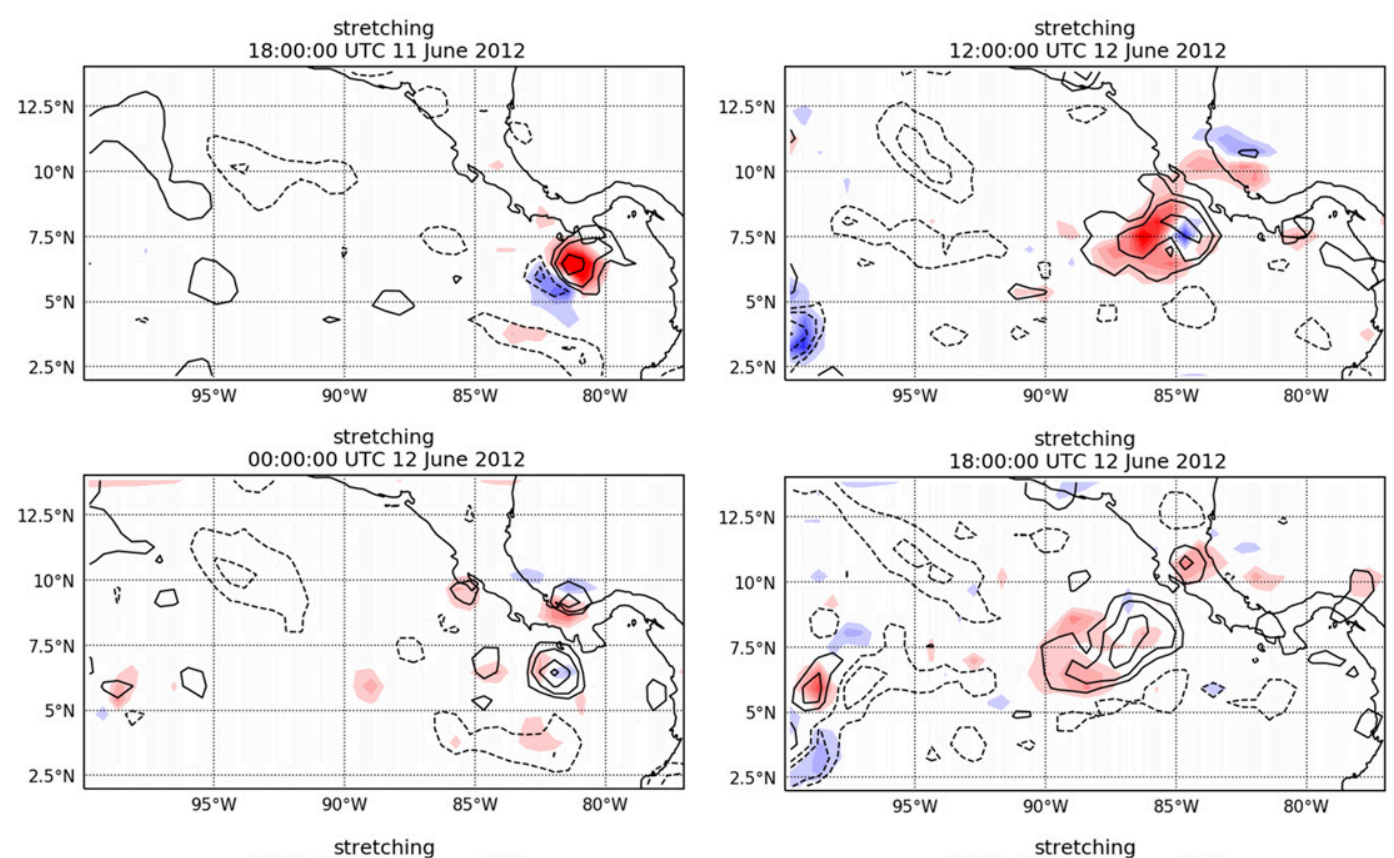

06:00:00 UTC 12 June 2012
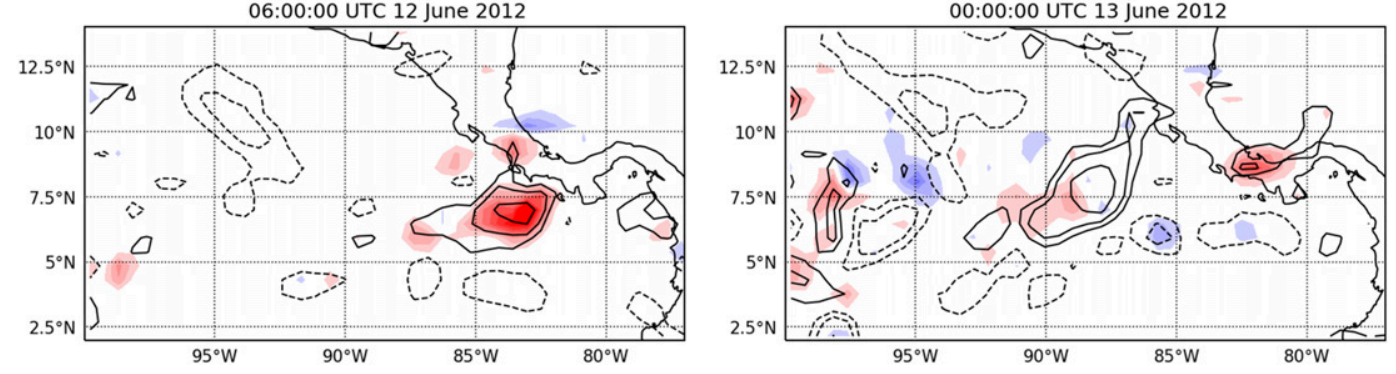

FIG. 8. WRF total $500 \mathrm{hPa}$ vorticity stretching $\left(\mathrm{s}^{-1} \mathrm{day}^{-1}\right.$; color contours) and anomalous $500 \mathrm{hPa}$ relative vorticity ( $\mathrm{s}^{-1}$; line contours). Relative vorticity contours are plotted for $\pm 2.5,5,10,15,25,45$, and $65 \times 10^{-5} \mathrm{~s}^{-1}$.

the disturbance at a given time and location, and then subtracting away the area-averaged time mean of the same current box location. The track of this vorticity maximum is shown in Fig. 1. By removing the model basic state, the profiles will focus on the development of the perturbation vortex. When analyzing the full variable fields to include the background state, the WRF budget term profiles are similar to those for the perturbation vortex (not shown).

Figure 9 shows that vortex intensification during the MCSto-EW transition is dominated by stretching between 800 and $400 \mathrm{hPa}$. Each vertical profile except for 1800 UTC 11 June has a positive maximum in stretching near $600 \mathrm{hPa}$ and the three highest values of stretching occur toward the end of the transition to an EW at 0600, 1200, and 1800 UTC 12 June. An analysis of the stretching term, $\eta \partial \omega / \partial p=\zeta_{z} \partial \omega / \partial p+f \partial \omega / \partial p$, indicates that the term with $\zeta_{z}$ is the dominant contributor to stretching when compared to the Coriolis parameter (not shown). Further, the $\zeta_{z}$ contributions to the stretching profiles in Fig. 9 are largely composed of vorticity from the EW anomaly or convection acting within the mesoscale vortex, rather than from the background vorticity (not shown). The shape of the stretching profiles suggests a top-heavy convective structure to the system where anomalous convergence is occurring in the middle troposphere, which is conducive to forming a midlevel vortex (e.g., Houze 2004; see Fig. 13). The top-heavy structure of the disturbance was also observed in a $2^{\circ} \times 2^{\circ}$ full-field analysis to incorporate the background state (not shown). Rydbeck et al. (2017) also identified that a topheavy heating structure was present in their analysis. On the other hand, horizontal advection is generally weak or negative during the MCS-to-EW transition and is strongly negative after an EW has formed in the final two profiles. Vortex tilting does not seem to play as large of a role in vortex development as the other two terms but does positively contribute to growth at lower levels at 1200 and 1800 UTC 12 June, possibly associated with shearing effects due to the Papagayo jet. Overall, vertical profiles of the budget terms point to the importance of convective coupling and a top-heavy structure in the EW genesis pathway for vorticity generation in this case study, as also seen in Figs. 5 and 8. 


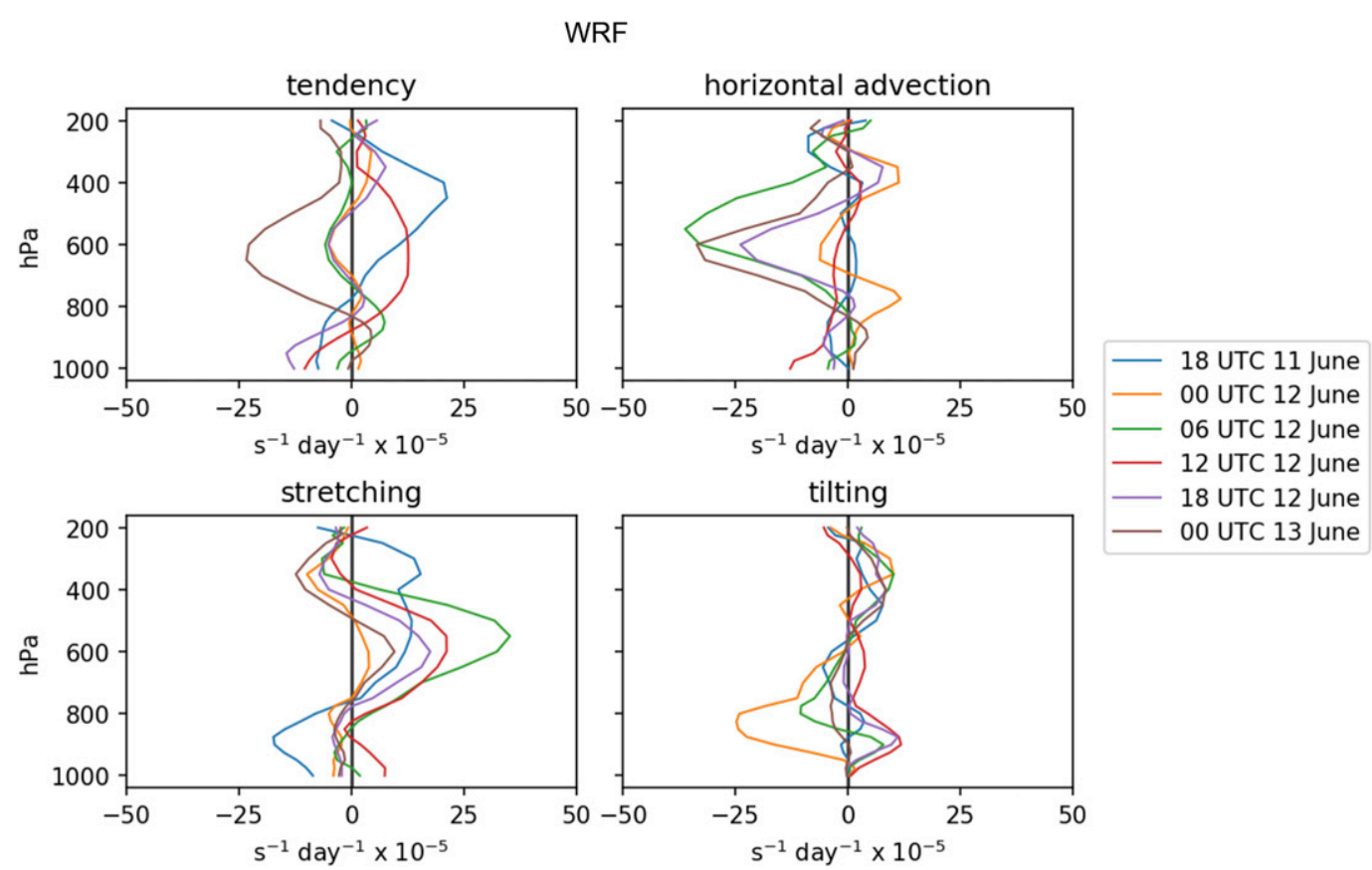

FIG. 9. Vertical profiles of average WRF vorticity budget term anomalies $\left(\mathrm{s}^{-1} \mathrm{day}^{-1} \times 10^{-5}\right)$ across an approximately $2^{\circ} \times 2^{\circ}$ box centered on the $500 \mathrm{hPa}$ vorticity maximum of the disturbance every $6 \mathrm{~h}$ starting at 1800 UTC 11 Jun 2012. Anomalies are relative to the time mean for the full simulation (1200 UTC 11 Jun to 0000 UTC 15 Jun 2012) over each respective box.

Vorticity budget results for ERA5 (not shown) are generally similar to those presented for WRF in Figs. 6-9; however, there are a few notable differences. First, the MCS vortex in ERA5 seems to expand early on through horizontal advection and has negative stretching at $500 \mathrm{hPa}$ during these times, which is not seen in WRF. Like in WRF, stretching is very important to the MCS-to-EW transition in ERA5, but stretching tends to have a more consistent impact on MCS upscale growth in the model than in observations. In terms of the budget vertical profiles, stretching in ERA5 tends to peak slightly higher in the middle troposphere than in the WRF, but there is also evidence of strong low-level stretching at 0000 UTC 13 June in ERA5 that does not occur in the model. This later signal has implications for interactions with wind jets, which maximize at low levels in this region. One interesting caveat to the WRF results in Fig. 9 is that when the box was expanded for a $5^{\circ} \times 5^{\circ}$ full-field analysis (not shown), there was an increase in low-level stretching and low-level heating, while still maintaining strong midlevel stretching and top-heaviness. This suggests the possibility of jet interactions and/or deep convection in WRF further away from the midlevel vortex and highlights some modest sensitivity of the results to the box size.

\section{Potential interactions with low-level wind jets}

The Chocó and Papagayo low-level jets have been shown to be important in the development of MCSs, EWs, and tropical cyclones (Serra et al. 2010; Holbach and Bourassa 2014; Zuluaga and Houze 2015). This section will investigate the behavior of these wind jets over the course of this case study, and test the hypothesis that the Papagayo jet, in particular, helps strengthen the developing MCS.

Figure 10 gives time series of the westerly Chocó and easterly Papagayo jet features in both ERA5 and the WRF simulation. As discussed above, the Chocó jet is defined as the average horizontal vector wind speed at $925 \mathrm{hPa}$ over $3^{\circ}-7^{\circ} \mathrm{N}$, $77^{\circ}-85^{\circ} \mathrm{W}$, while the $925 \mathrm{hPa}$ Papagayo jet wind speed is averaged over the same area that was used in Whitaker and Maloney $\left(2018,9^{\circ}-13^{\circ} \mathrm{N} ; 86^{\circ}-89^{\circ} \mathrm{W}\right)$. In ERA5, both the Papagayo and Chocó jets are relatively weak six to three days before the mature MCS at 1200 UTC 11 June, having wind speeds below $6 \mathrm{~m} \mathrm{~s}^{-1}$. Over the following couple of days, the Papagayo jet strengthens to over $8 \mathrm{~m} \mathrm{~s}^{-1}$ at 0000 UTC 10 June and then weakens over the next $24 \mathrm{~h}$. Meanwhile, the Chocó jet strengthens by roughly $4 \mathrm{~m} \mathrm{~s}^{-1}$ over $24 \mathrm{~h}$ starting at 1200 UTC 10 June and then maximizes to a wind speed of $6 \mathrm{~m} \mathrm{~s}^{-1}$ at 1200 UTC 11 June, when the MCS has formed over the Panama Bight and when the WRF simulation begins. The Papagayo jet begins to greatly intensify as the MCS convection develops, starting around 0000 UTC 11 June. By the time the MCS has formed $12 \mathrm{~h}$ later, the jet wind speed is up to around $10 \mathrm{~m} \mathrm{~s}^{-1}$.

Looking at times following the WRF simulation start time, both ERA5 and WRF show that the Chocó jet steadily weakens as the MCS disturbance propagates away from the South American coast. However, the Papagayo jet continues to strengthen during the MCS-to-EW transition (which occurs between 0000 and 1800 UTC 12 June) while the disturbance moves to the northwest toward Costa Rica and the jet region. 


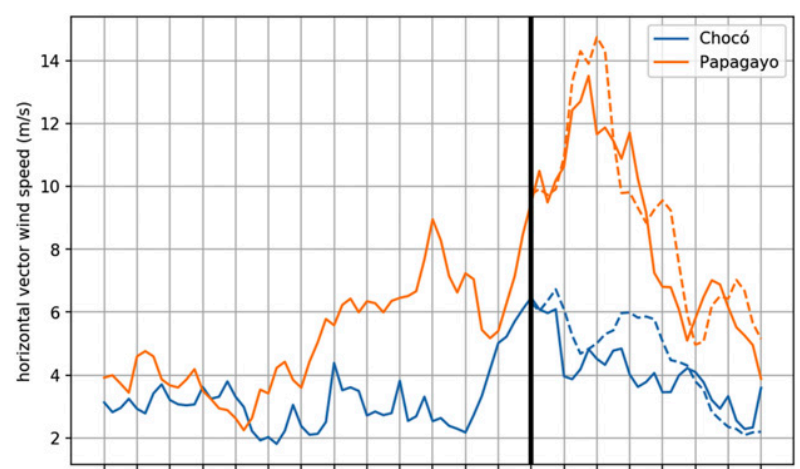

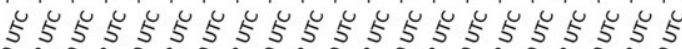

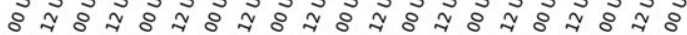

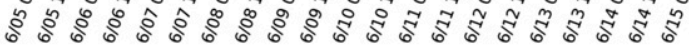

time

FIG. 10. Horizontal vector wind speed $\left(\mathrm{m} \mathrm{s}^{-1}\right)$ at $925 \mathrm{hPa}$ for the Papagayo (orange) and Chocó (blue) jets in ERA5 (solid) and WRF (dashed). The black vertical line at 1200 UTC 11 Jun 2012 represents the start of the WRF simulation.

In both reanalysis and the model, the Papagayo jet intensifies by about $4 \mathrm{~m} \mathrm{~s}^{-1}$ from 1200 UTC 11 June to 1200 UTC 12 June and maximizes around $14 \mathrm{~m} \mathrm{~s}^{-1}$. In fact, looking from the time of initial MCS convective activity at 0000 UTC 11 June, ERA5 documents an almost $8 \mathrm{~m} \mathrm{~s}^{-1}$ increase in the jet to its maximum strength a day and a half later. In the hours after peak jet strength, the disturbance completes its transition into an EW and the jet weakens. Finally, as the EW continues propagating to the northwest and eventually forms Carlotta, ERA5 and WRF show that the strength of the Papagayo jet greatly tapers off.

Figure 11 shows the evolution of $925 \mathrm{hPa}$ geopotential height (with the average diurnal cycle removed), $925 \mathrm{hPa}$ vorticity anomalies (relative to the 0000 UTC 5 June-2100 UTC 19 June time mean), and the total unfiltered $925 \mathrm{hPa}$ wind during the MCS-to-EW transition in ERA5. In the first two panels on 10 June, the weakness of the easterly Papagayo jet is evident, even though the broader Caribbean low-level jet can be observed further to the east. Further, the Chocó jet begins to set up on 10 June with westerly flow occurring around $5^{\circ} \mathrm{N}$ by 2100 UTC, and an increase in jet strength highlighted in Fig. 10. Over the next $24 \mathrm{~h}$ during 11 June, the initiated MCS convection seen in Fig. 2 becomes apparent in the geopotential height anomalies, with low pressure and stronger westerlies in the Panama Bight. Additionally, the Papagayo jet is more prominent by 2100 UTC 11 June, with the lower-level vorticity feature extending out from the Central American coast and a stronger meridional pressure gradient associated with the strong high pressure anomalies to the north on the Caribbean

ERA5
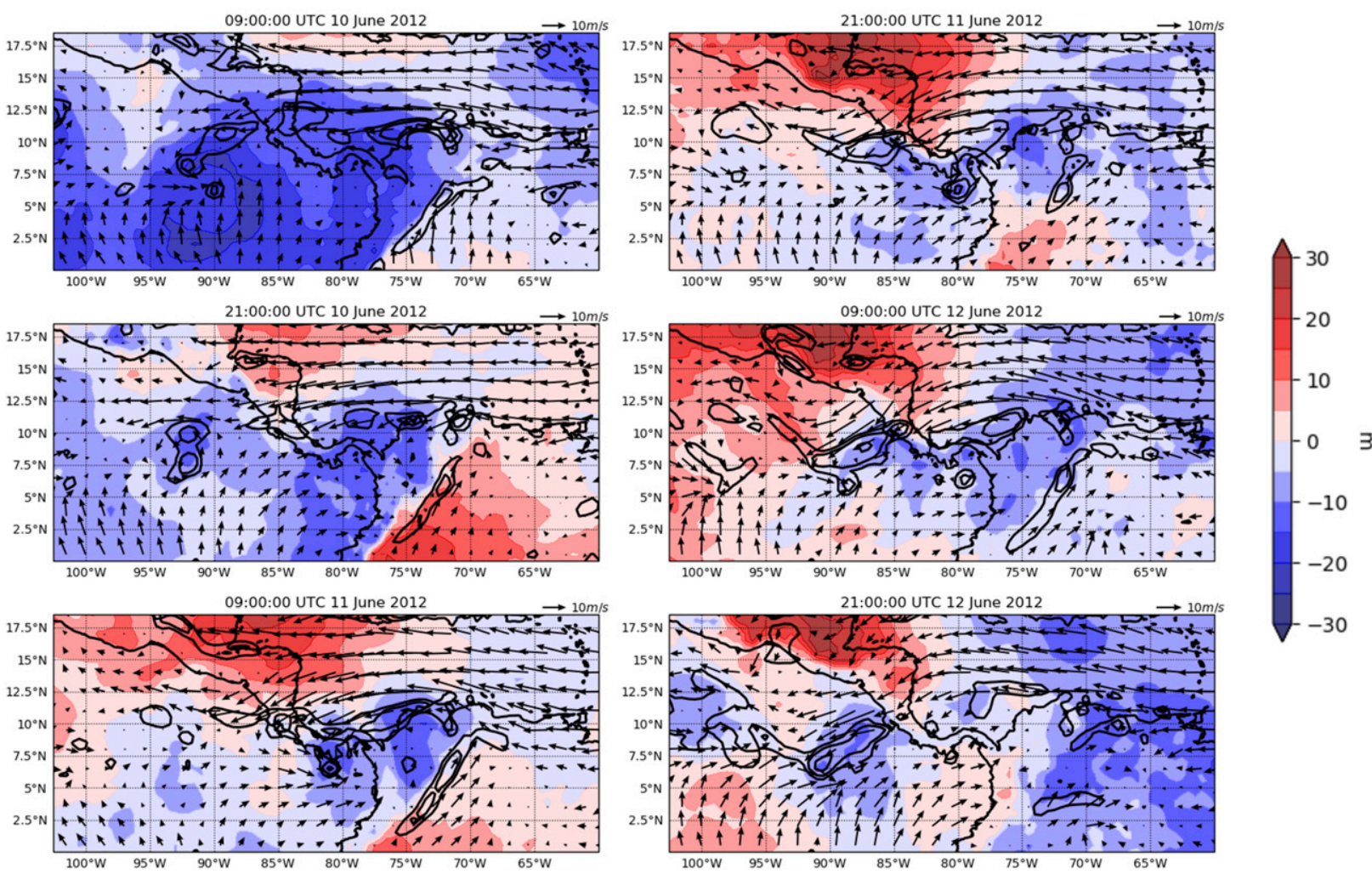

09:00:00 UTC 11 June 2012

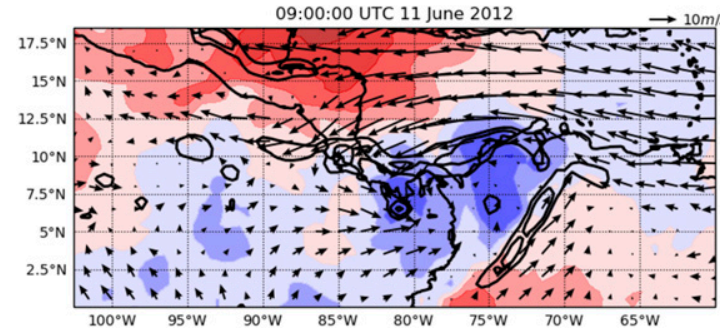

FIG. 11. ERA5 $925 \mathrm{hPa}$ geopotential height with the average diurnal cycle removed (m; color contours), $925 \mathrm{hPa}$ relative vorticity anomalies ( $\mathrm{s}^{-1}$; line contours), and $925 \mathrm{hPa}$ wind ( $\mathrm{m} \mathrm{s}^{-1}$; vectors; reference vector of $10 \mathrm{~m} \mathrm{~s}^{-1}$ in the upper right of each panel). Vorticity contours are plotted for $2.5,5,10,15,25,45$, and $65 \times 10^{-5} \mathrm{~s}^{-1}$. 


\section{WRF}
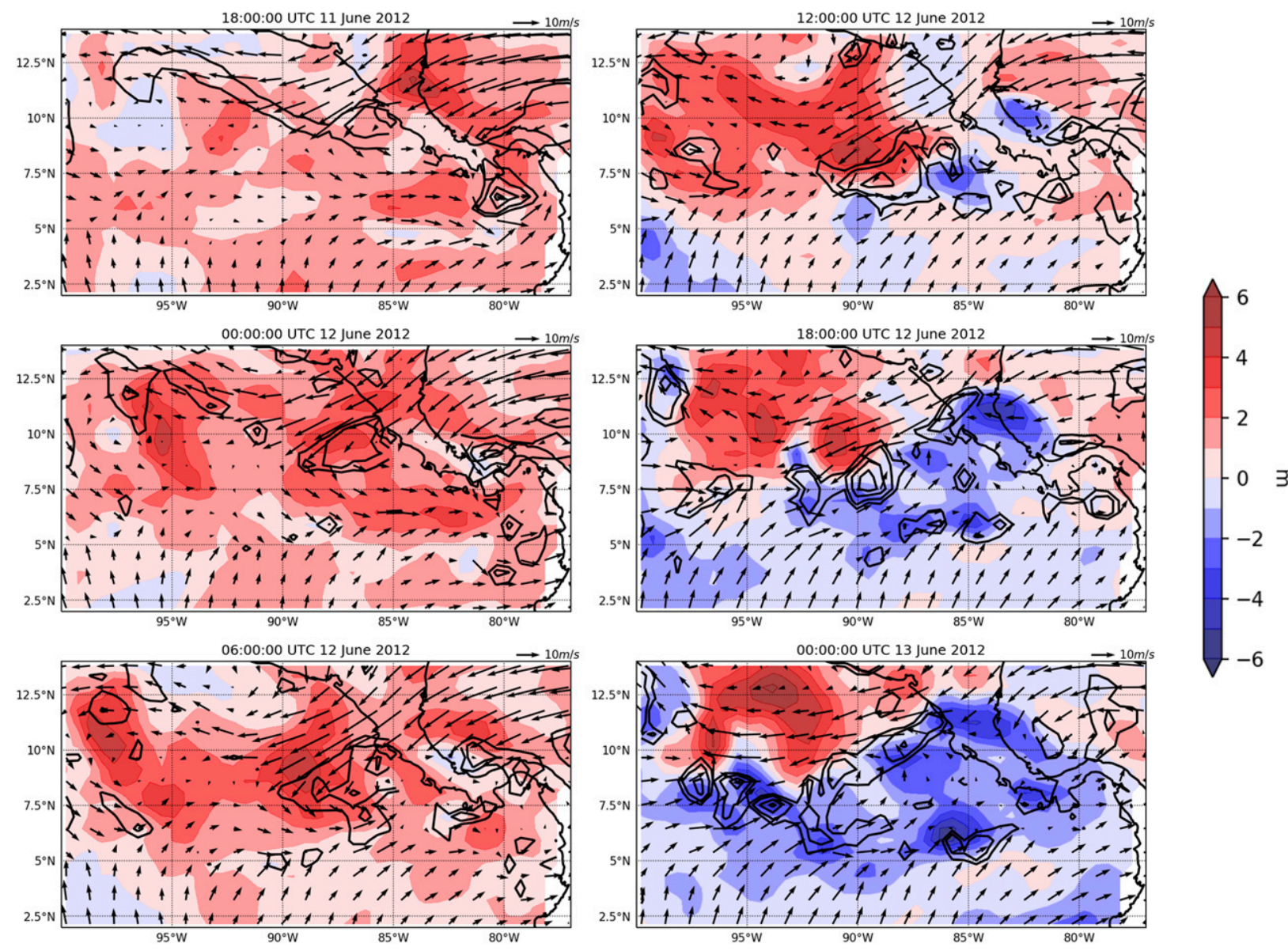

FIG. 12. WRF $925 \mathrm{hPa}$ geopotential height with the average diurnal cycle removed (m; color contours), $925 \mathrm{hPa}$ relative vorticity anomalies ( $\mathrm{s}^{-1}$; line contours), and $925 \mathrm{hPa}$ wind $\left(\mathrm{m} \mathrm{s}^{-1}\right.$; vectors; reference vector of $\left.10 \mathrm{~m} \mathrm{~s}^{-1}\right)$. Vorticity contours are plotted for $2.5,5,10$, $15,25,45$, and $65 \times 10^{-5} \mathrm{~s}^{-1}$.

side of Central America and the weak low pressure anomalies in the east Pacific. A pressure gradient across the Central American terrain has been shown to lead to an intensification of gap wind features (Schultz et al. 1997), while a fluctuation of the trade winds may also be supporting the Papagayo jet (Chelton et al. 2000). During the MCS-to-EW transition from 0000 to 1800 UTC 12 June, the Papagayo jet reaches its maximum strength over the case study region and is accompanied by enhanced low-level vorticity. At 0900 UTC 12 June, the transitioning disturbance is still to the southeast of the jet and the low-level vorticity anomaly; a broad low pressure anomaly that is likely aided by the MCS continues to support the overall pressure gradient across the Papagayo gap. At 2100 UTC 12 June, an elongated $925 \mathrm{hPa}$ vorticity feature extends to the southwest from the coastline and the recently formed EW vorticity feature is starting to become almost collocated with it (not shown). Thus, the low pressure anomaly of the MCS during its evolution appears to have aided a broader pressure gradient that was set up by the Caribbean high pressure anomalies, and this pressure gradient likely forced the enhanced Papagayo gap flow. This enhanced easterly gap flow, coupled with the monsoon trough westerlies produced positive low-level shear vorticity on the equatorward side of the jet for the system to interact with, as described in Holbach and Bourassa (2014). Holbach and Bourassa (2014) also found that surface vorticity generated by the Papagayo jet supports TC genesis.

Figure 12 shows the $925 \mathrm{hPa}$ evolution of the wind jets and geopotential height (with the average diurnal cycle removed) in WRF. Early on during the MCS stage, the Chocó jet is apparent, directing westerly flow toward the disturbance. During the MCS-to-EW transition from 0000 to 1800 UTC 12 June, the Papagayo jet undergoes a similar progression as in ERA5 (Fig. 11), with positive shear vorticity being generated to the south of the jet. This low-level vorticity feature is out in front of the midlevel vortex highlighted in Figs. 1 and 6-8, possibly limiting its interaction with the core of the disturbance and differing from the near collocation noted for ERA5 above. So, while WRF and ERA5 have similar jet structures and evolutions, differences in vertical profiles between the cases may be important to potential interactions, as will be discussed next. 


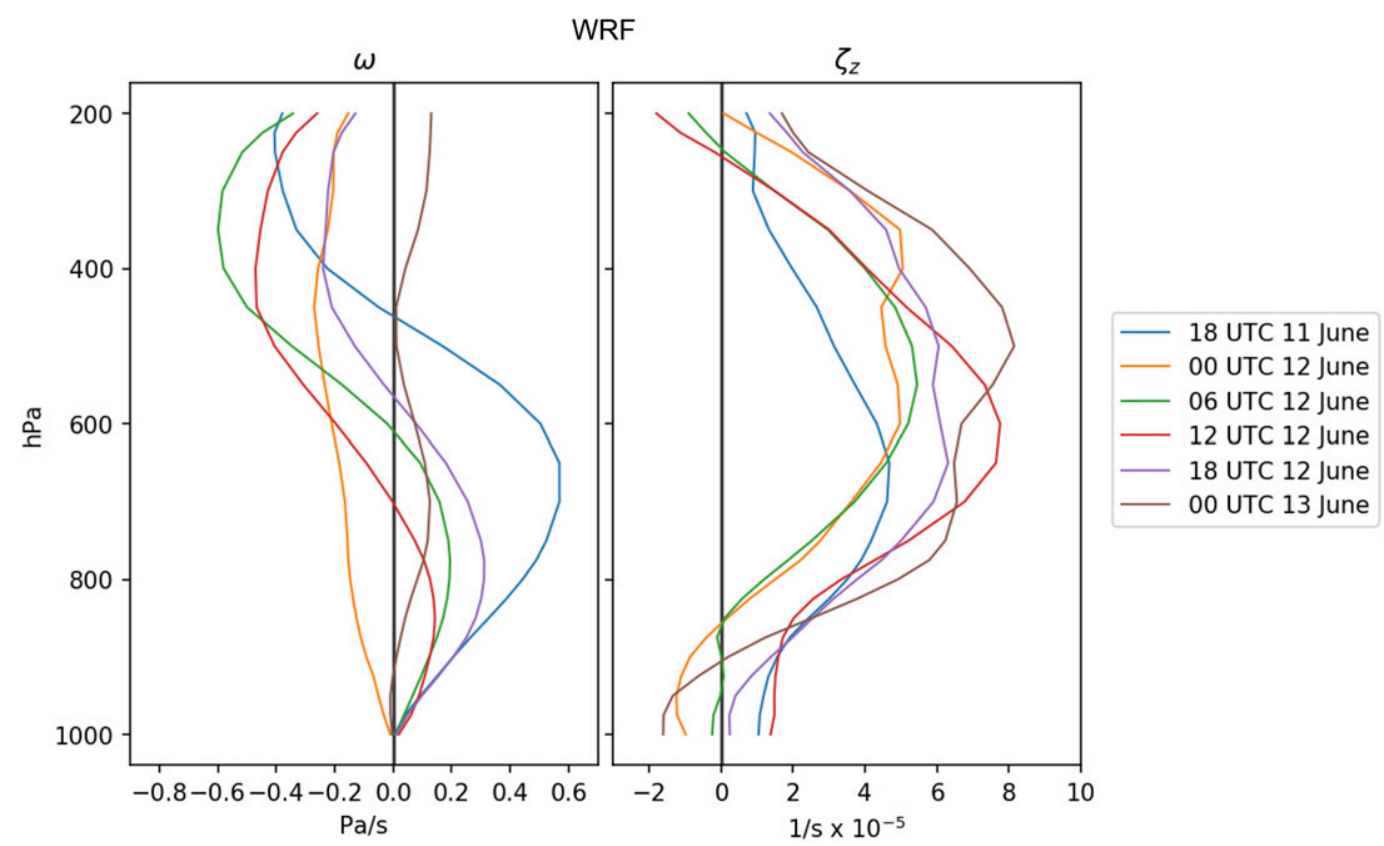

FIG. 13. Vertical profiles of average WRF omega and vertical vorticity anomalies $\left(\mathrm{Pa} \mathrm{s}^{-1}\right.$ and s $\mathrm{s}^{-1} \times 10^{-5}$, respectively) across an approximately $2^{\circ} \times 2^{\circ}$ box centered on the $500 \mathrm{hPa}$ vorticity maximum of the disturbance every $6 \mathrm{~h}$ starting at 1800 UTC 11 Jun 2012. Anomalies are relative to the time mean for the full simulation (1200 UTC 11 Jun to 0000 UTC 15 Jun 2012) over each respective box.

Figures 13 and 14 show vertical profiles of the centered, area-averaged anomalies of $\omega$ and vorticity for the disturbance across a $2^{\circ} \times 2^{\circ}$ region in WRF and ERA5, respectively. Figure 13 shows that the developing disturbance in WRF generally has upward vertical motion at upper levels and downward motion at lower levels, indicative of a stratiform structure. In particular, this anomalous top-heavy structure is supported by a full-field analysis of omega and Q1 (apparent heat source) that shows that the overall structure of the disturbance including the background state is also top-heavy (not shown). Coupled with this structure is a consistent vorticity profile that peaks at midlevels. Although the midlevel vortex intensifies over the course of the MCS-to-EW transition, there does not seem to be a strong increase in anomalous low-level vorticity across the profiles, which suggests that interactions with the Papagayo jet during this time do not produce a positive vorticity tendency beneath the midlevel center, and is consistent with a vertical velocity structure that suggests anomalous divergence in the lower troposphere. Figure 9 also supports this notion, with positive stretching mostly being confined to midlevels. Although there is some evidence of positive tilting at the level of the jet (Fig. 9), a low-level spinup due to the jet is not reflected in the WRF vorticity profiles (Fig. 13). An analysis of the stretching term points to the vertical relative vorticity of the vortex itself being more important to intensification when compared to the environmental vorticity (not shown). So, the stratiform structure of the disturbance is persistent throughout the transition into an EW in WRF.

In reanalysis, Fig. 14 shows that vertical velocity profiles are generally not as top-heavy as in WRF. This feature also holds for a full-field $2^{\circ} \times 2^{\circ}$ analysis of omega and Q1 that includes the background state, suggesting overall stronger low-level vertical motion in ERA5 versus WRF (not shown). Low-level convergence is suggested from the anomalous vertical velocity profiles in ERA5 for several of the times, suggesting positive vorticity generation at low-levels. During the final two profiles, the low-level vorticity increases, indicating that the system may be interacting with the low-level vorticity anomaly associated with the Papagayo jet shown in Fig. 11. This interaction with the jet comes around the time the EW has formed, and thus may be more important to the development of the EW rather than the transition of the MCS. So, while the disturbance in WRF is more top-heavy with a midlevel vortex, the reduced top-heaviness of the ERA5 disturbance along with the timing of the midlevel vortex may be allowing for stronger interactions with the Papagayo jet. Interestingly, both sets of anomalous omega profiles suggest that as the system develops, the profiles become less top-heavy near the vortex center, which could be due to the system transitioning into an EW from an MCS. In EWs, deep convection plays a more important role in supporting the disturbance and is maintained by moisture advection from the EW circulation (Rydbeck and Maloney 2015). Again, there is some sensitivity to the size of the averaging box used. For example, in WRF a $5^{\circ} \times 5^{\circ}$ full-field analysis finds that stronger low-level upward vertical motion and enhanced low-level vorticity occur in the vertical profiles, although the Q1 and omega profiles are still top-heavy. This highlights some sensitivity to these findings and indicates that potential jet interactions and deep convection could be occurring farther away from the midlevel vortex center. On the other hand, the 


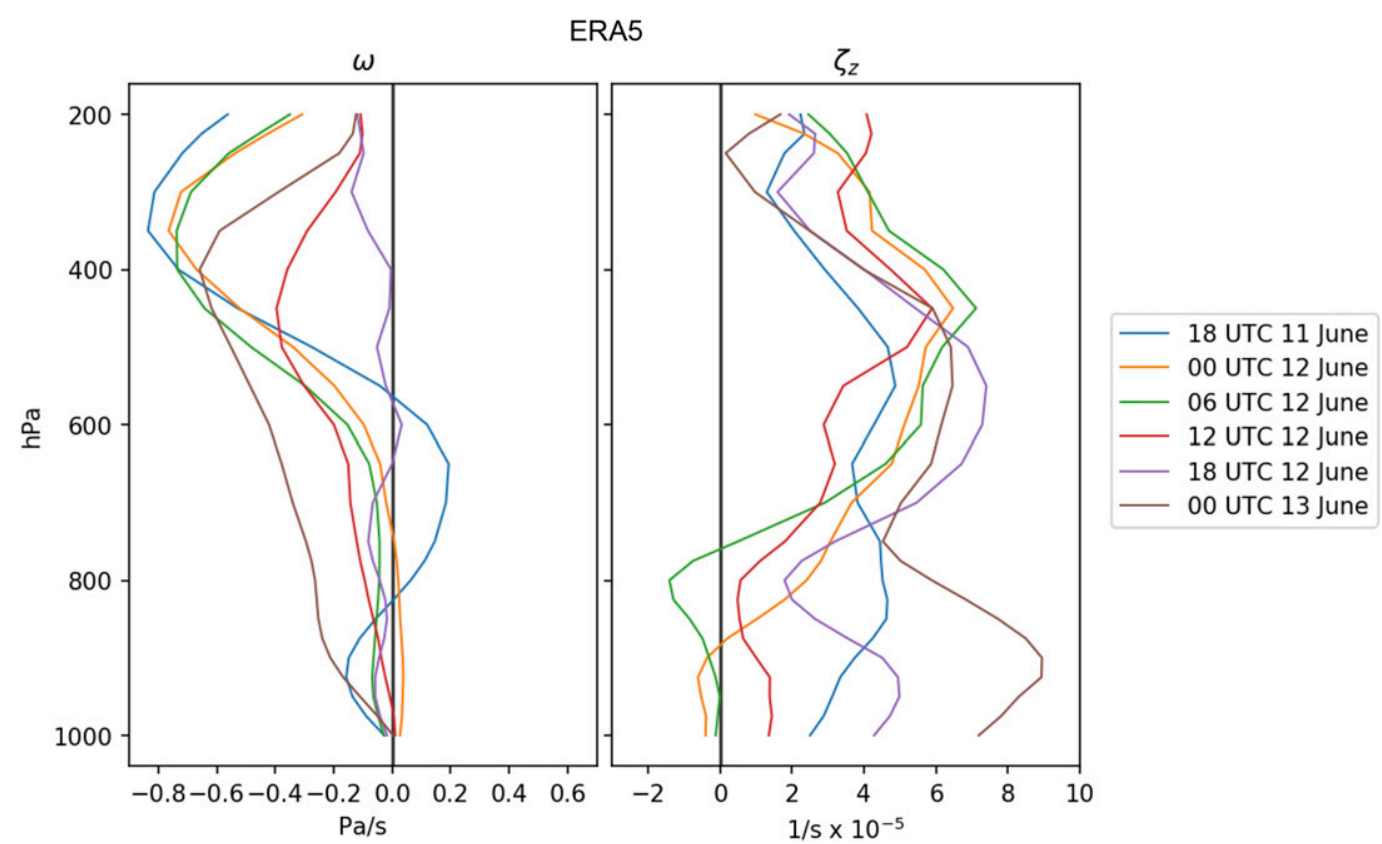

FIG. 14. Vertical profiles of average ERA5 omega and vertical vorticity anomalies $\left(\mathrm{Pa} \mathrm{s}^{-1}\right.$ and s $^{-1} \times 10^{-5}$, respectively) across a $2^{\circ} \times 2^{\circ}$ box centered on the $500 \mathrm{hPa}$ vorticity maximum of the disturbance every $6 \mathrm{~h}$ starting at 1800 UTC 11 Jun 2012. Anomalies are relative to the time mean for 0000 UTC 5 Jun to 2100 UTC 19 Jun 2012 over each respective box.

anomalous profiles for the perturbation vortex at the $5^{\circ} \times 5^{\circ}$ box size do not show much low-level vertical motion and have some increased low-level vorticity (not shown).

For the same disturbance, ERA5 and WRF have differing vertical motion profiles near the maximum of the midlevel vortex. These differences have important implications, such as the model supporting a midlevel vortex through a primarily stratiform structure and ERA5 providing opportunities for convection and vorticity generation at lower levels. In addition, the shape of the vertical motion profiles in the disturbance are important to understanding interactions with the Papagayo jet, where shear vorticity has been generated to the south of the jet (Holbach and Bourassa 2014). Low-level upward motion in the vicinity of the jet shear vorticity anomaly would lead to additional vorticity generation there. Thus, field observations like those collected during OTREC (e.g., Fuchs-Stone et al. 2020) will be important to improving our understanding of the vertical structure of east Pacific disturbances and their representation in models and reanalyses. What east Pacific vertical convective structure looks like was one of the primary motivations for OTREC. Given the parameterized nature of convection in ERA5 and the relatively data-poor east Pacific, we are not confident that vorticity budget processes are necessarily better represented in ERA5 versus the model that has higher-resolved convective processes and improved representation of the complex topography of this region.

\section{Discussion}

The formation of east Pacific EWs encompasses an array of remote and local factors. While a traditional view is that east
Pacific EWs are simply African EWs that have entered the basin (e.g., Frank 1970; Pasch et al. 2009), other studies have proposed several mechanisms for EW genesis in the basin without a precursor wave (e.g., Ferreira and Schubert 1997; Toma and Webster 2010; Rydbeck et al. 2017). One such mechanism is the upscale growth of Panama Bight MCSs, investigated in a modeling study by Rydbeck et al. (2017). The present study reaffirms this type of EW genesis by providing a case study of this process, and analyzes an MCS-to-EW transition that occurred on 11-12 June 2012 with a WRF simulation at convective-permitting scales.

Echoing the findings of Kerns et al. (2008) and Rydbeck et al. (2017), the Panama Bight MCS vortex was able to grow as it moved northwestward, with vortex stretching being a key aspect of the process. Vortex stretching associated with convective processes, and top-heavy structures in particular, is the driver of the MCS transition into an EW, supporting Rydbeck et al. (2017), while horizontal advection is associated with the propagation of the system with positive advection leading the advancing vortex and negative advection trailing it. Positive vortex stretching regions occur within and on the southwest and northeast portions of the system vorticity anomaly, which allows the smaller MCS vortex to intensify, expand, and tilt its wave axis, assisting the transition into a structure resembling an EW. Rydbeck and Maloney (2015) show that convection in the southwest and northeast regions of an EW supports the tilting of a wave and leads to continued wave growth.

Anomalous vertical profiles of stretching, vertical motion, and relative vorticity near the midlevel vortex maximum highlight that the MCS growth process in this case seems to be 
primarily associated with stratiform structures. Positive stretching occurs at midlevels, which acts on and subsequently strengthens a midlevel vortex. In the WRF simulation, Fig. 13 shows that the peak vorticity at the EW stage (the final profile) is almost double that of the peak vorticity at the MCS stage (the first profile). Figure 5 highlights that precipitation is fairly collocated with the developing vortex, and combined with the findings of a consistent top-heavy structure and strong midlevel stretching, precipitation processes seem to have a strong influence on the growth of the disturbance.

In addition to conducting a vorticity budget on the developing MCS, the possible interactions of low-level wind jets with the growth process were investigated. Similar to the findings of Zuluaga and Houze (2015), a strong Chocó jet is present as the MCS forms, with the horizontal vector wind speed increasing by $4 \mathrm{~m} \mathrm{~s}^{-1}$ in ERA5 from 1200 UTC 10 June to 1200 UTC 11 June in the buildup to the MCS forming (Fig. 10). In addition, Fig. 10 shows that the Papagayo jet reaches its peak intensity around one day after the MCS has formed, both in observations and in the model. Figures 13 and 14 emphasize that the disturbance in WRF is more top-heavy than in ERA5 and that the ERA5 disturbance has an increase in low-level vorticity during the later anomalous profiles, while the vorticity in the simulated system remains concentrated at midlevels. In light of the less top-heavy vertical motion profiles, implied low-level convergence, and the increase in low-level vorticity, there is evidence of stronger possible interactions with the Papagayo jet in ERA5 near the location of the midlevel vorticity maximum. Field observations from OTREC will be useful for better understanding the shape and variability of vertical motion profiles of developing disturbances as well as investigating interactions with the Papagayo and Chocó jets. For example, Fuchs-Stone et al. (2020) found that bottomheavy profiles generally occurred during OTREC, which provides support to ERA5's interactions with the Papagayo jet as reflected in the ERA5 results and serves as a caveat to WRF, although these events occurred over different time periods. Further modeling that spans a larger number of EW development cases will also help to address this issue. A caveat to these results is the selection of averaging box size. While a smaller box size focuses on the development of the primary midlevel vortex, a larger box size could be useful in examining more exterior impacts on the disturbance. While the results in this study highlight a strong stratiform profile in the WRF system, an analysis with a larger box size suggests that deep convection as well as interactions with the Papagayo jet could be relatively more prominent farther from the midlevel center.

While this case study gives additional context to the MCS to EW mechanism proposed by Rydbeck et al. (2017), many questions still remain, for example: How often does this process occur in a given hurricane season? Why do some Panama Bight MCSs develop into EWs and not others? Can we improve our forecasts of EWs and possibly even hurricanes by knowing more about this process? To this end, additional studies of this process, which will be aided by observations gathered during the OTREC field campaign in summer 2019, are necessary to improve our understanding of east Pacific EW activity.
Acknowledgments. We thank George Kiladis and two anonymous reviewers for their helpful reviews that improved this manuscript. This work was supported by the Climate and Large-Scale Dynamics 631 Program of the National Science Foundation under Grant AGS-1735978. We acknowledge the use of imagery from the NASA Worldview application (https://worldview.earthdata.nasa.gov/) operated by the NASA/Goddard Space Flight Center Earth Science Data and Information System (ESDIS) project. The ERA5 data in this study were generated using Copernicus Climate Change Service Information 2018. Neither the European Commission nor ECMWF is responsible for any use that may be made of the Copernicus Information or data it contains. We would like to acknowledge high-performance computing support from Cheyenne (doi:10.5065/D6RX99HX) provided by NCAR's Computational and Information Systems Laboratory, sponsored by the National Science Foundation.

Data availability statement. Data and model output used in this manuscript can be made available upon request.

\section{REFERENCES}

Adames, A. F., and Y. Ming, 2018: Interactions between water vapor and potential vorticity in synoptic-scale monsoonal disturbances: Moisture vortex instability. J. Atmos. Sci., 75, 2083-2106, https://doi.org/10.1175/JAS-D-17-0310.1.

C3S, 2017: ERA5: Fifth generation of ECMWF atmospheric reanalyses of the global climate. Copernicus Climate Change Service Climate Data Store, accessed 3 May 2018, https:// cds.climate.copernicus.eu/cdsapp\#!/home.

Chelton, D. B., M. H. Freilich, and S. K. Esbensen, 2000: Satellite observations of the wind jets off the Pacific coast of Central America. Part I: Case studies and statistical characteristics. Mon. Wea. Rev., 128, 1993-2018, https://doi.org/10.1175/15200493(2000)128\%3C1993:SOOTWJ\%3E2.0.CO;2.

Collins, W. D., and Coauthors, 2004: Description of the NCAR Community Atmosphere Model (CAM 3.0). NCAR Tech. Note NCAR/TN-464+STR, 214 pp., https://doi.org/10.5065/ D63N21CH.

Crosbie, E., and Y. Serra, 2014: Intraseasonal modulation of synoptic-scale disturbances and tropical cyclone genesis in the eastern North Pacific. J. Climate, 27, 5724-5745, https:// doi.org/10.1175/JCLI-D-13-00399.1.

Dunkerton, T. J., M. T. Montgomery, and Z. Wang, 2009: Tropical cyclogenesis in a tropical wave critical layer: Easterly waves. Atmos. Chem. Phys., 9, 5587-5646, https://doi.org/10.5194/ acp-9-5587-2009.

Feng, Z., L. R. Leung, R. A. Houze Jr., S. Hagos, J. Hardin, Q. Yang, B. Han, and J. Fan, 2018: Structure and evolution of mesoscale convective systems: Sensitivity to cloud microphysics in convection-permitting simulations over the United States. J. Adv. Model. Earth Syst., 10, 1470-1494, https:// doi.org/10.1029/2018MS001305.

Ferreira, R. N., and W. H. Schubert, 1997: Barotropic aspects of ITCZ breakdown. J. Atmos. Sci., 54, 261-285, https://doi.org/ 10.1175/1520-0469(1997)054<0261:BAOIB > 2.0.CO;2.

Frank, N. L., 1970: Atlantic tropical systems of 1969. Mon. Wea. Rev., 98, 307-314, https://doi.org/10.1175/1520-0493(1970) 098<0307:ATSO > 2.3.CO;2.

Fuchs-Stone, Ž., D. J. Raymond, and S. Sentić, 2020: OTREC2019: Convection over the east Pacific and southwest Caribbean. 
Geophys. Res. Lett., 47, e2020GL087564, https://doi.org/10.1029/ $2020 \mathrm{gl} 1087564$.

Holbach, H. M., and M. A. Bourassa, 2014: The effects of gapwind-induced vorticity, the monsoon trough, and the ITCZ on east Pacific tropical cyclogenesis. Mon. Wea. Rev., 142, 13121325, https://doi.org/10.1175/MWR-D-13-00218.1.

Hong, S.-Y., Y. Noh, and J. Dudhia, 2006: A new vertical diffusion package with an explicit treatment of entrainment processes. Mon. Wea. Rev., 134, 2318-2341, https://doi.org/10.1175/MWR3199.1.

Houze, R. A., Jr., 2004: Mesoscale convective systems. Rev. Geophys., 42, RG4003, https://doi.org/10.1029/2004RG000150.

Joyce, R. J., J. E. Janowiak, P. A. Arkin, and P. Xie, 2004: CMORPH: A method that produces global precipitation estimates from passive microwave and infrared data at high spatial and temporal resolution. J. Hydrometeor., 5, 487-503, https://doi.org/10.1175/1525-7541(2004)005<0487: CAMTPG $>2.0 . \mathrm{CO} ; 2$.

Kerns, B., K. Greene, and E. Zipser, 2008: Four years of tropical ERA-40 vorticity maxima tracks. Part I: Climatology and vertical vorticity structure. Mon. Wea. Rev., 136, 4301-4319, https://doi.org/10.1175/2008MWR2390.1.

Maloney, E. D., and D. L. Hartmann, 2000: Modulation of eastern North Pacific hurricanes by the Madden-Julian oscillation. J. Climate, 13, 1451-1460, https://doi.org/10.1175/1520-0442(2000) 013<1451:MOENPH > 2.0.CO;2.

— dynamics, and North Pacific tropical cyclone formation. Part I: Observations. J. Atmos. Sci., 58, 2545-2558, https://doi.org/ 10.1175/1520-0469(2001)058<2545:TMJOBD>2.0.CO;2.

Mapes, B. E., T. T. Warner, M. Xu, and A. J. Negri, 2003a: Diurnal patterns of rainfall in northwestern South America. Part I: Observations and context. Mon. Wea. Rev., 131, 799-812, https:// doi.org/10.1175/1520-0493(2003)131<0799:DPORIN>2.0.CO;2.

,$- \ldots$, and,$- 2003 \mathrm{~b}$ : Diurnal patterns of rainfall in northwestern South America. Part III: Diurnal gravity waves and nocturnal convection offshore. Mon. Wea. Rev., 131, 830-844, https:// doi.org/10.1175/1520-0493(2003)131<0830:DPORIN>2.0.CO;2.

Molinari, J., and D. Vollaro, 2000: Planetary- and synoptic-scale influences on eastern Pacific tropical cyclogenesis. Mon. Wea. Rev., 128, 3296-3307, https://doi.org/10.1175/1520-0493(2000) 128<3296:PASSIO >2.0.CO;2.

—, D. Knight, M. Dickinson, D. Vollaro, and S. Skubis, 1997: Potential vorticity, easterly waves, and eastern Pacific tropical cyclogenesis. Mon. Wea. Rev., 125, 2699-2708, https://doi.org/ 10.1175/1520-0493(1997)125<2699:PVEWAE > 2.0.CO;2.

Mozer, J. B., and J. A. Zehnder, 1996: Lee vorticity production by large-scale tropical mountain ranges. Part I: Eastern North Pacific tropical cyclogenesis. J. Atmos. Sci., 53, 521-538, https://doi.org/ 10.1175/1520-0469(1996)053<0521:LVPBLS > 2.0.CO;2.

Pasch, R. J., and D. A. Zelinsky, 2012: Tropical Cyclone Report Hurricane Carlotta (EP032012) 14-16 June 2012. National Hurricane Center Rep., 13 pp., https://www.nhc.noaa.gov/ data/tcr/EP032012_Carlotta.pdf.

— , and Coauthors, 2009: Eastern North Pacific hurricane season of 2006. Mon. Wea. Rev., 137, 3-20, https://doi.org/10.1175/ 2008MWR2508.1.

Petersen, W. A., R. Cifelli, D. J. Boccippio, S. A. Rutledge, and C. Fairall, 2003: Convection and easterly wave structures observed in the eastern Pacific warm pool during EPIC-2001. J. Atmos. Sci., 60, 1754-1773, https://doi.org/10.1175/15200469(2003)060<1754:CAEWSO > 2.0.CO;2.

Poveda, G., and O. J. Mesa, 2000: On the existence of Lloró (the rainiest locality on Earth): Enhanced ocean-land-atmosphere interaction by a low level jet. Geophys. Res. Lett., 27, 16751678, https://doi.org/10.1029/1999GL006091.

Rasmussen, K. L., and R. A. Houze, 2016: Convective initiation near the Andes in subtropical South America. Mon. Wea. Rev., 144, 2351-2374, https://doi.org/10.1175/MWR-D-150058.1.

Rydbeck, A. V., and E. D. Maloney, 2014: Energetics of east Pacific easterly waves during intraseasonal events. J. Climate, 27, 7603-7621, https://doi.org/10.1175/JCLI-D-14-00211.1.

— organization of east Pacific easterly waves. J. Atmos. Sci., 72, 3850-3870, https://doi.org/10.1175/JAS-D-15-0056.1.

— - — , and G. J. Alaka, 2017: In situ initiation of east Pacific easterly waves in a regional model. J. Atmos. Sci., 74, 333-351, https://doi.org/10.1175/JAS-D-16-0124.1.

Schultz, D. M., W. E. Bracken, L. F. Bosart, G. J. Hakim, M. A. Bedrick, M. J. Dickinson, and K. R. Tyle, 1997: The 1993 superstorm cold surge: Frontal structure, gap flow, and tropical impact. Mon. Wea. Rev., 125, 5-39, https://doi.org/10.1175/ 1520-0493(1997)125<0005:TSCSFS > 2.0.CO;2.

Serra, Y. L., G. N. Kiladis, and M. F. Cronin, 2008: Horizontal and vertical structure of easterly waves in the Pacific ITCZ. J. Atmos. Sci., 65, 1266-1284, https://doi.org/10.1175/ 2007JAS2341.1.

,-- , and K. I. Hodges, 2010: Tracking and mean structure of easterly waves over the intra-Americas sea. J. Climate, 23, 4823-4840, https://doi.org/10.1175/2010JCLI3223.1.

Shapiro, L. J., 1986: The three dimensional structure of synoptic-scale disturbances over the tropical Atlantic. Mon. Wea. Rev., 114, 1876-1891, https://doi.org/10.1175/1520-0493(1986)114<1876: TTDSOS $>2.0 . \mathrm{CO} ; 2$.

Skamarock, W. C., and Coauthors, 2008: A description of the Advanced Research WRF version 3. NCAR Tech. Note NCAR/TN-475+STR, 113 pp., https://doi.org/10.5065/ D68S4MVH.

Tewari, M., and Coauthors, 2004: Implementation and verification of the unified Noah land surface model in the WRF Model. 20th Conf. on Weather Analysis and Forecasting/16th Conf. on Numerical Weather Prediction, Seattle, WA, Amer. Meteor. Soc., 14.2A, https://ams.confex.com/ams/84Annual/ techprogram/paper_69061.htm.

Thompson, G., P. R. Field, R. M. Rasmussen, and W. D. Hall, 2008: Explicit forecasts of winter precipitation using an improved bulk microphysics scheme. Part II: Implementation of a new snow parameterization. Mon. Wea. Rev., 136, 5095-5115, https://doi.org/10.1175/2008MWR2387.1.

Thorncroft, C., and K. Hodges, 2001: African easterly wave variability and its relationship to Atlantic tropical cyclone activity. J. Climate, 14, 1166-1179, https://doi.org/10.1175/ 1520-0442(2001)014<1166:AEWVAI > 2.0.CO;2.

_ , N. M. J. Hall, and G. N. Kiladis, 2008: Three-dimensional structure and dynamics of African easterly waves. Part III: Genesis. J. Atmos. Sci., 65, 3596-3607, https://doi.org/10.1175/ 2008JAS2575.1.

Toma, V. E., and P. J. Webster, 2010: Oscillations of the intertropical convergence zone and the genesis of easterly waves. Part I: Diagnostics and theory. Climate Dyn., 34, 587-604, https://doi.org/10.1007/s00382-009-0584-x.

Torres, V. M., and C. D. Thorncroft, 2018: Genesis of easterly waves over the intra Americas seas and the tropical eastern Pacific. 33rd Conf. on Hurricanes and Tropical Meteorology, Ponte Vedra, FL, Amer. Meteor. Soc., 8A.7, https://ams.confex.com/ ams/33HURRICANE/webprogram/Paper340265.html. 
Velasco, I., and J. M. Fritsch, 1987: Mesoscale convective complexes in the Americas. J. Geophys. Res., 92, 9591-9613, https://doi.org/10.1029/JD092iD08p09591.

Wang, C., and G. Magnusdottir, 2006: The ITCZ in the central and eastern Pacific on synoptic time scales. Mon. Wea. Rev., 134, 1405-1421, https://doi.org/10.1175/MWR3130.1.

Whitaker, J. W., and E. D. Maloney, 2018: Influence of the Madden-Julian oscillation and Caribbean low-level jet on east Pacific easterly wave dynamics. J. Atmos. Sci., 75, 1121-1141, https://doi.org/10.1175/JAS-D-17-0250.1.

Yepes, J., G. Poveda, J. F. Mejía, L. Moreno, and C. Rueda, 2019: CHOCO-JEX: A research experiment focused on the Chocó low-level jet over the far eastern Pacific and western Colombia. Bull. Amer. Meteor. Soc., 100, 779-796, https:// doi.org/10.1175/BAMS-D-18-0045.1.

Zehnder, J. A., 1991: The interaction of planetary-scale tropical easterly waves with topography: A mechanism for the initiation of tropical cyclones. J. Atmos. Sci., 48, 1217-1230, https://doi.org/10.1175/1520-0469(1991)048<1217: TIOPST $>2.0 . \mathrm{CO} ; 2$.

Zuluaga, M. D., and R. A. Houze Jr., 2015: Extreme convection of the near-equatorial Americas, Africa, and adjoining oceans as seen by TRMM. Mon. Wea. Rev., 143, 298-316, https://doi.org/ 10.1175/MWR-D-14-00109.1. 